\title{
Methodology to estimate the break force of pharmaceutical tablets with curved faces under diametrical compression
}

\author{
M. Al-Sabbagh ${ }^{a, b}$, P. Polak ${ }^{a}$, R.J. Roberts ${ }^{c}$, G.K. Reynolds ${ }^{c}$, I.C. Sinka ${ }^{a^{*}}$ \\ a Department of Engineering, University of Leicester, University Road, Leicester, LE1 7RH, UK \\ ${ }^{\mathrm{b}}$ Department of Mechanical Engineering, Al-Mustansiriyah University, Baghdad, Iraq \\ ${ }^{\mathrm{c}}$ Pharmaceutical Technology \& Development, AstraZeneca, Macclesfield, SK10 2NA, UK \\ *ics4@le.ac.uk, Tel: +44 1162522555
}

Revised manuscript submitted to International Journal of Pharmaceutics

16 September 2018

\begin{abstract}
This paper develops a methodology to estimate the break force of curved faced tablets under diametrical compression. Common excipients used in pharmaceutical tablet formulations, including microcrystalline cellulose, calcium phosphate and mannitol as well as their mixtures were characterised. Compacts of different densities were manufactured and their compressive and tensile strength was measured. The break force of curved face tablets having a comprehensive range of face curvatures and thickness was measured using the diametrical compression method ("hardness" test). Equation $\sigma_{d}=\frac{F}{\pi D^{2}}\left(a \frac{t}{D}+b \frac{W}{D}\right)^{-1}$ introduced by Shang et al. (2013) was used to relate the break force $(F)$ to tablet geometry $(D, t, W)$ and material tensile strength $\left(\sigma_{d}\right)$. Here, we propose a method to estimate the parameters $a$ and $b$ using data for curved faced tablets made from three pure excipients. The method was validated for four mixtures. The errors were analysed and compared with the USP29 method $\sigma_{d}=\frac{10 F}{\pi D^{2}}(2.84(t / D)-0.126(t / W)+3.15(W / D)+0.01)^{-1}$. The proposed method has better accuracy, however, requires additional characterisation of the compressive strength of the material.
\end{abstract}

\section{Keywords}

Diametrical compression test, powder, tablet, tensile strength, break force

\section{Introduction}

Pharmaceutical tablets are manufactured using the process of compaction, whereby a powder formulation is introduced into a die and pressed into a tablet using punches. Tablets must have sufficient mechanical integrity to allow post-compaction operations including handling, coating, packaging etc. yet deliver the drug by either rapidly disintegrating after administration or in a controlled manner over time. 
The mechanical strength of the tablets is a key quality attribute that is monitored during manufacturing and appears on batch records for regulatory reasons. The standard method for characterising the strength of the tablets consists of the diametrical compression test, or so called "hardness" test, which is standardised as described in USP29-NF24 (United States Pharmacopoeia). The diametrical compression test is an indirect method used to determine the tensile strength of a material and originated from rock mechanics materials (Hudson et al., 1972) where it was introduced as the "Brazilian" test (Carneiro and Barcellos, 1953) and (Akazawa, 1953). It has subsequently been employed in the pharmaceutical industry (Fell and Newton, 1970 ; Pitt et al., 1988; Shang et al., 2013; Wang et al., 2004), the ceramics industry (Shetty et al., 1986), for testing of metal composites (Wang, 2007), and other brittle materials.

The theoretical framework for the indirect tensile test is provided by Hertz (Timoshenko and Goodier, 1970) who analysed the stress state in a thin disk made of a linear elastic material subject to line loading across the diameter. The geometry of the disk is as illustrated in Figure $1 \mathrm{a}$.

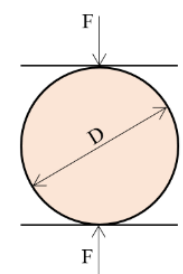

(a)

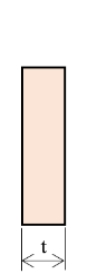

(b)

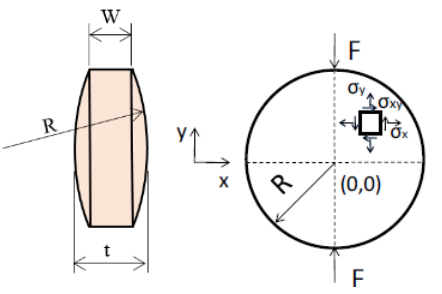

(c)

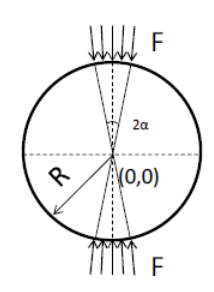

(e)

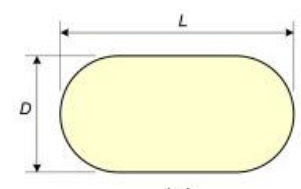

(c)

(f)

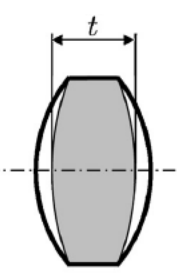

(g)

Figure 1 Diametrical compression test

a) geometry of a thin disk subject to diametrical compression,

b) geometry of cross-section of a thin disk with flat faces,

c) geometry of cross-section of a thin disks with curved faces (Shang et al., 2013),

d) stresses in a thin flat disk under point loading (Hertz, 1895),

e) Thin disk subject to distributed loading (Hondros, 1959),

f) Geometry of elongated tablets (Pitt and Heasley, 2013),

g) Effective cross section of curved faced tablets (Razavi et al., 2015)

Under point loading condition the elastic stresses developed in the thin disk (Hertz 1895;

Timoshenko and Goodier, 1970) are

$$
\begin{aligned}
& \sigma_{x}=\frac{-2 F}{\pi t}\left\{\frac{x^{2}(D / 2-y)}{\beta_{1}^{4}}+\frac{x^{2}(D / 2+y)}{\beta_{2}^{4}}-\frac{1}{D}\right\} \\
& \sigma_{y}=\frac{-2 F}{\pi t}\left\{\frac{(D / 2-y)^{3}}{\beta_{1}^{4}}+\frac{(D / 2+y)^{3}}{\beta_{2}^{4}}-\frac{1}{D}\right\} \\
& \sigma_{x y}=\frac{2 F}{\pi t}\left\{\frac{x(D / 2-y)^{2}}{\beta_{1}^{4}}+\frac{x(D / 2+y)^{2}}{\beta_{2}^{4}}\right\}
\end{aligned}
$$

where $\beta_{1}^{2}=(D / 2-y)^{2}+x^{2}, \beta_{2}^{2}=(D / 2+y)^{2}+x^{2}, \sigma_{x}$ and $\sigma_{y}$ are the normal stresses in the perpendicular and parallel directions to the loading, respectively, and $\sigma_{x y}$ is the in-plane shear stress illustrated in Figure 1d, and 
$F$ - force required to break the tablet, which will be called $F_{d}$,

$D$ - diameter of the disk (tablet),

$t$ - the thickness of the disk (tablet),

The maximum principal stress occurs in the disk centre along the $x$-direction and is tensile. It is assumed that specimen failure is governed by the maximum tensile principal stress. The tensile strength $\sigma_{x}$ which will be henceforth referred to as $\sigma_{d}$, is obtained for $x=y=0$ :

$$
\sigma_{x}=\sigma_{d}=\frac{2 F}{\pi D t}
$$

Under this tensile stress the tablets break diametrically into two similar halves (Podczeck, 2012). Other patterns of tablet breakage (Newton et al., 1971) can be observed when the stress state deviates from the Hertz solution.

However, in practice the tablet deforms to conform to the loading platen (contact flattening is taking place) and the point loading assumption of the Hertz solution becomes invalid. Hondros (1959) adapted the work of Hertz in order to represent the distributed loading condition as shown in Figure 1e. The Hondros stress solution when $x=0$ and $y=0$ is:

$$
\begin{aligned}
& \sigma_{x}(0, y), \sigma_{y}(0, y)= \pm \frac{2 F}{\alpha \pi D t}\left[\frac{\left(1-\frac{r^{2}}{R^{2}}\right) \sin 2 \alpha}{\left(1 \mp 2 r^{2} / R^{2} \cos 2 \alpha+\frac{r^{4}}{R^{4}}\right)} \mp \tan ^{-1}\left(\frac{1 \pm \frac{r^{2}}{R^{2}}}{1 \mp \frac{r^{2}}{R^{2}}} \tan \alpha\right)\right] \\
& \sigma_{x}(x, 0), \sigma_{y}(x, 0)=\mp \frac{2 F}{\alpha \pi D t}\left[\frac{\left(1-\frac{r^{2}}{R^{2}}\right) \sin 2 \alpha}{\left(1 \mp 2 r^{2} / R^{2} \cos 2 \alpha+\frac{r^{4}}{R^{4}}\right)} \pm \tan ^{-1}\left(\frac{1 \pm \frac{r^{2}}{R^{2}}}{1 \mp \frac{r^{2}}{R^{2}}} \tan \alpha\right)\right] \\
& \tau_{x y}(0, y), \tau_{x y}(x, 0)=0
\end{aligned}
$$

where $r$ is the radial distance from the point to the centre.

In the Hondros theory the compressive stress is finite at the point $y=R$. At the disk centre, the stress in $x$-direction is

$$
\sigma_{x}(0,0)=\frac{2 F}{\pi D t \alpha}(\sin 2 \alpha-\alpha)
$$

As $\sin 2 \alpha \approx 2 \alpha$ for small $\alpha$, this reduces to the Hertz solution.

The disks subject to diametrical compression, however, have a finite thickness. Doremus et al. (2001) studied the influence of the thickness $t$ and the diameter of the samples $D$ on the failure stress. According to this study, the aspect ratio of the specimen should satisfy the ratio $t / D \leq 0.25$ for the purpose of making sure that the assumptions of the Hertz theory are adequately satisfied. 
At this point it can be concluded that Equation (4) can be used for thin disks ( $t / D \leq 0.25$ ) illustrated in Figure $1 \mathrm{a}, \mathrm{b}$. This is a key result, as it means the tensile strength of a material can be determined by performing a diametrical compression test on a thin disk with flat faces.

Typical tablets are designed to have curved faces with single or multiple curvatures and the dies are often not round but elongated, square, triangular or various other shapes with rounded vertices. For such tablets the break force is measured using the same apparatus as for thin disks under diametrical compression. However, for complex shapes analytical solutions (e.g. Hertz, Hondros) do not exist, thus the tensile strength of the material can no longer be estimated using relationships such as Equation 4 ; instead empirical relationships have been developed as discussed below.

Figures 1a,c illustrate the geometry of a round tablet with curved faces subject to diametrical compression. Pitt et al. (1989) established an empirical relationship between the break force, geometric parameters, and the material tensile strength of specimens of convex shaped gypsum discs:

$$
\sigma_{d}=\frac{10 F}{\pi D^{2}}(2.84(t / D)-0.126(t / W)+3.15(W / D)+0.01)^{-1}
$$

where

$t$ - (total) thickness of the tablet

$W$ - band width of the tablet

$R$ - radius of curvature of the tablet face

Equation 9 can be used to determine the material tensile strength as a function of normalised geometric terms $(t / D, t / W, W / D)$ which have fixed numerical values as indicated in the equation. This relationship has become industry standard and was included in USP (USP, 2011a). It has been established by the authors that Equation 9 is valid if $0.1 \leq W / D \leq 0.3$ and $D / R<1$.

Pitt et al. (1989) and Haririan and Newton (1999) presented the practical use of Equation (9) for materials other than gypsum: aspirin tablets and microcrystalline cellulose tablets, respectively. They argued the dependence of the strength of the material on porosity, commenting that the flaw and porosity distributions might have an influence on the results. More recently, Pitt and Heasley (2013) extended the use of Equation 9 to elongated shaped tablets illustrated in Figure 1a, f. Using finite element analysis they showed that as the ratio of length to diameter was increased the stress reached a limiting value 2/3 that of a circular tablet, hence proposed a modification to Equations 4 and 9, respectively, as:

$$
\begin{aligned}
\sigma_{d} & =\frac{2}{3} \frac{2 F}{\pi D t} \\
\sigma_{d} & =\frac{2}{3} \frac{10 F}{\pi D^{2}}(2.84(t / D)-0.126(t / W)+3.15(W / D)+0.01)^{-1}
\end{aligned}
$$

Shang et al. (2013) wrote the original equation of Pitt in a generalised form as:

$$
\sigma_{d}=\frac{F}{\pi D^{2}}(a(t / D)+b(t / W)+c(W / D)+d)^{-1}
$$


where coefficients $a, b, c$, and $d$ are to be determined empirically. They observed that Equation (9) does not reduce to the Hertz solution in the case of flat tablets, out of the three dimensionless terms only two are independent and that the empirical coefficients depend on compaction pressure.

A comprehensive set of experiments were performed by Shang et al. (2013) to determine the break force for tablets with a wide range of curvatures manufactured at a variety of compaction pressures from a single powder material (microcrystalline cellulose). They processed the data as in the original paper by Pitt et al. (1988) and found that the fitting parameters $a, b, c$, and $d$ were different from those in Equation 9. They also found that there was a significant difference between the coefficients for tablets manufactured using different levels of compaction pressure. However, this does not mean that the coefficients depend on the compaction pressure necessarily. Shang et al. (2013) normalised the break force of the tablet which is pressed to a given density with respect to density using a reference force

$$
F_{\text {ref }}=\sigma_{d} * \frac{\pi A}{2}
$$

where $A$ is the tablet cross-sectional area, which can be determined according to the Equation 14 using the nondimensional geometric parameters (Shang et al., 2013a).

$$
A=D^{2}\left[2\left(\frac{t}{D}-\frac{W}{D}\right)\left(\frac{\left(\frac{t}{D}-\frac{W}{D}\right)^{2}}{16}+\frac{1}{3}\right)+\frac{W}{D}\right]
$$

The normalised force can be defined as:

$$
\bar{F}=F / F_{\text {ref }}
$$

The reference force in Equation 15 is expressed as a function of the tensile strength of the material and cross section area of the curved faced tablet. This equation can be used for both flat faced tablets and curved faced tablets. For flat faced tablets, Equation (13) recovers the Hertz solution, in which case the normalised force equals unity and $A=D t$. In effect, for curved faced tablets, the break force is normalised with respect to the break force of a thin tablet of the same density and the same cross-sectional area. In doing so, the tensile strength of the material is eliminated.

Furthermore, Shang et al. (2013a) proposed a two parameter model:

$$
\sigma_{d}=\frac{F}{\pi D^{2}}\left(a \frac{t}{D}+b \frac{W}{D}\right)^{-1}
$$

where $a$ and $b$ are fitting parameters derived from the experimental data. Equation (16) reduces to Hertz's solution when $a+b=0.5$.

Podczeck et al. (2013) used elastic and elasto-plastic finite element analysis to evaluate the failure of doubly-convex tablets developed a general equation to calculate the tensile strength of doublyconvex tablets from the failure load $(P)$. The tablet geometry used is consistent with Figure $1 \mathrm{a}, \mathrm{c}$.

$$
\sigma_{d}=\left(\frac{2 P}{\pi D W}\right)\left(\frac{W}{t}\right)=2 P / \pi D t
$$


Equation (17) reduces to the Hertz solution for flat faced tables.

Razavi et al. (2015) proposed a general framework to determine tensile strength under diametrical compression for doubly convex tablets. This approach is based on that the observation that the tensile strength is directly proportional to the break force and inversely proportional to a non-linear function of material properties and geometric parameters. This generalization also reduces to the Hertz solution and to the empirical relationship used for convex shaped tablets. Two models were identified by Razavi et al. (2015) namely the mechanistic interpretation and a generalised model. The general equation is:

$$
\sigma_{t}=\frac{F}{\pi D^{2} Q}
$$

where $\sigma_{t}$ is the tensile strength, and the geometry notations are consistent with Figure 1a,c. $Q$ is a nonlinear function of material properties and geometric parameters. For flat faced tablets, $Q=t / 2 D$ when the tablet is subjected to concentrated loads (Timoshenko and Goodier, 1970), while $Q=$ $t / 2 D\left[1-(b / D)^{2}\right]^{3 / 2}$ when the tablet is subjected to a load distributed uniformly on a stripe of width $b$ (Tang, 1994).

For simplicity, Razavi et al. (2015) assumed a form for $Q$ as:

$$
Q=a\left(\frac{t}{D}\right)^{e}+b\left(\frac{t}{W}\right)^{f}+c\left(\frac{W}{D}\right)^{g}+d
$$

where $Q \rightarrow t / 2 D$ as $W \rightarrow t$, for the purpose of enforcing the correct limit for flat faced tablets. Equation (18) becomes:

$$
\sigma_{t}=\frac{F}{\pi D^{2}\left[a\left(\frac{t}{D}\right)^{e}+b\left(\frac{t}{W}\right)^{f}+c\left(\frac{W}{D}\right)^{g}+d\right]}
$$

where the parameters $a, b, c, d, e, f$ and $g$ are assumed to be known or can be estimated using experiments set observations, the similar to the generalisation of Shang et al., (2013a) but includes four additional empirical parameters.

In the mechanistic interpretation, the problem is recast in terms of a surface with effective crosssectional area $\bar{A}$, which is related to the tensile strength as follows:

$$
\sigma_{t}=\frac{2 F}{\pi \bar{A}}
$$

where $\bar{A}=t D$ for flat tablets (Hertz solution). For curved faced tablets, Razavi et al. (2015) parameterized $\bar{A}$ by $\bar{t}$ (Figure $1 \mathrm{~g}$ ) which is an effective thickness as follows:

$$
\bar{A}=D^{2}\left[2\left(\frac{\bar{t}}{D}-\frac{W}{D}\right)\left\{\frac{1}{3}+\frac{1}{15}\left(\frac{\bar{t}}{D}-\frac{W}{D}\right)^{2}\right\}+\frac{W}{D}\right]+\mathcal{O}\left(\frac{(\bar{t}-W)^{5}}{D^{3}}\right)
$$


This parametrization is made for simplicity. Assuming that $\bar{t} / D$ depends on $D / R$, in the form of:

$$
\frac{\bar{t}}{D}=\frac{W}{D}+\alpha\left(\frac{D}{R}\right)^{\beta}\left(\frac{t}{D}-\frac{W}{D}\right)
$$

where $\alpha>0$ and $\beta \geq 0$ are fitting parameters, a new relationship between tensile strength, break force and geometric parameters is obtained:

$$
\sigma_{t}=\frac{2 F}{\pi D^{2}\left[2 \alpha\left(\frac{D}{R}\right)^{\beta}\left(\frac{t}{D}-\frac{W}{D}\right)\left\{\frac{1}{3}+\frac{\alpha^{2}}{15}\left(\frac{D}{R}\right)^{2 \beta}\left(\frac{t}{D}-\frac{W}{D}\right)^{2}\right\}+\frac{W}{D}\right]}
$$

At this point it can be concluded that the estimation of the break force of curved faced tablet can be predicted using a number of equations which all include empirical parameters. As most of the models reviewed above were developed based on experiments using on a single powder material, is not clear if the empirical parameters present in the models are material dependent or not.

The stress distribution within a tablet loaded under diametrical compression is complex even for the simplest geometry of a flat faced disk, as illustrated by Equation 1-3 developed by Hertz for linear elastic materials. Different assumptions for the loading conditions lead to Equations 5-7 developed by Hondros. Furthermore, finite element analysis (FEA) was used by Procopio and Zavaliangos (2003) to evaluate the effect contact flattening and material properties on estimating the stress leading to breakage; showing that the magnitude and location of the maximum stress changes depending on the plasticity model used. The use of finite element analysis has been explored to estimate the break force of complex shaped tablets too: Equation 17 is based on the finite element calculations by Podczeck et al. (2013). Equations 10-11 result from FEA by Pitt and Heasley (2013). Shang et al. (2013b) used FEA analysis with different constitutive models and failure criteria suggesting that the parameters of Equation 16 may be material dependent and the plastic deformation at the contact points plays a role. Thus finite element analysis can be used to compute the stress in a curved faced tablet considering increased levels of complexity arising from loading conditions, contact flattening, material constitutive law and failure criteria, etc. but each specific geometry and material requires separate simulations. FEA also has significant input data requirements to calibrate a constitutive model and other input parameter which are detailed next.

In the above discussion it is assumed that the tablet is homogeneous, which is not the case in practice. Tablets can contain cracks (Wu, 2005) and present non-homogeneous density distributions which can be evidenced by a range of experimental characterisation techniques, including X-ray CT (Sinka, 2004a), NMRI (Sinka and Dejemai 2006), indentation hardness mapping (Sinka, 2003). Inhomogeneity originates from the tablet compaction process as a result of the interplay between the following five factors: constitutive behaviour of the powder during compaction, friction between powder and die wall, sequence of punch motions, initial condition of the powder in the die after die fill prior to compaction, and naturally, tablet geometry. The combined influence of these factors can be analysed by finite element models developed for powder compaction (Sinka, 2003). Density inhomogeneity is important because it affects the break force under diametrical compression. Sinka et al. (2004b) demonstrated that it is possible to engineer identical tablets in terms of size and weight from the same material, but with different internal density distributions which lead to different break force. Therefore, for accurate prediction of the break force of a tablet under diametrical compression, the entire process must be considered and such analysis requires significant numerical modelling as well as material characterisation effort. 
For reasons of such complexity, pragmatic methods currently used in industrial practice are based on empirical equations, for example the USP method uses Equation 9. The main objective of this paper is to develop and validate a method to estimate the break force of curved faced tablets considering a representative range of pharmaceutical excipients and mixtures, typical tablet densities and punch curvatures. The methodology used is similar to the USP method and use material characterisation procedures that are relatively modest compared to the requirements needed for finite element analysis.

\section{Materials}

Three commonly used pharmaceutical excipient powders (mannitol, calcium phosphate and microcrystalline cellulose) were chosen for model development in order to cover different compaction mechanisms, e.g. polymeric particles are assumed undergo plastic deformation originating from the contacts between particles, while the compaction of ceramics is believed to be controlled by particle rearrangement. Mixtures and lubricated powders are used for model validation.

\subsection{Mannitol}

Mannitol (Pearlitol 200SD) is used widely in food products and pharmaceutical formulations. The material can be easily dried thus it is often chosen for wet granulation processes. Mannitol is also used as an excipient in chewable tablet formulations because of its negative enthalpy of solution, agreeable texture and sweetness, which is approximately half as sweet as sucrose and as sweet as glucose.

Mannitol occurs as an odourless, white, free flowing granular or crystalline powder. When crystallised from an alcohol solution, its microscopic form is that of orthorhombic needles, though it also shows polymorphism. A typical particle size distribution for mannitol includes a maximum of $0.1 \%$ of particles with particle size greater than $500 \mu \mathrm{m}$ and a minimum of $90 \%$ with size greater than $200 \mu \mathrm{m}$ (Rowe et al., 2009). The bulk and full densities of the mannitol powder are indicated in Table 1. Figure 2a shows the shape form of the mannitol powder particles obtained using a Scanning Electron Microscope (SEM).

\subsection{Dibasic calcium phosphate}

Dibasic calcium phosphate (Trade name "A-Tab", manufactured by Rhodia Pharma Solutions) is powder used as a pharmaceutical excipient, due to its pharmacological inactivity, low cost and good compaction properties. Calcium phosphate is an odourless, white, crystalline solid, or tasteless powder. It is non-hygroscopic and stable at room temperature. Calcium phosphate is classed as a ceramic powder. Particles of calcium phosphate have a rough surface and an average diameter of approx. $180 \mu \mathrm{m}$ (Shang et al. 2013; Rowe et al., 2009). The bulk density and full density of the calcium phosphate powder are listed in Table 1. Figure $2 b$ shows an SEM image of the particles. For simplicity, this material is referred to as calcium phosphate in this paper.

\subsection{Microcrystalline cellulose}

Microcrystalline cellulose (MCC) grade PH102 (manufactured by FMC Biopolymer, Belgium) is widely used in food products and oral pharmaceutical formulations. MCC grade $\mathrm{PH} 102$ is specifically designed for formulations intended to be processed by direct compression. $\mathrm{MCC}$ materials are irregular with a typical mean size of $100 \mu \mathrm{m}$ and typical size distribution in the range 20-200 $\mu \mathrm{m}$. The 
form of MCC particles is shown in Figure 2c. MCC is a purified, partly depolymerized cellulose occurring as odourless, tasteless, white, crystalline powder formed of porous particles (Shang et al. 2013; Rowe et al., 2009). The bulk density and full density of MCC are listed in Table 1.

\subsection{Mixtures}

Four mixtures were used for model validation, including 50/50 w/w mixtures of mannitol/MCC and mannitol/dibasic calcium phosphate, and mannitol with 0.5 and $1 \%$ magnesium stearate. The full and bulk densities were calculated using the rules of mixtures for 2 materials ( $A, B)$ shown in Equation 24. The full and bulk densities for the mixtures of materials are listed in Table 1.

$$
\rho_{A B}=\frac{1}{\frac{x}{\rho_{A}}+\frac{1-x}{\rho_{B}}}
$$

where $\rho$ is the density and $x$ represents mass fraction (for the 50/50 w/w mixtures $x=0.5$ ).

The initial relative density $\left(R D_{\text {initial }}\right)$ is defined as the solid volume fraction:

$$
R D_{\text {initial }}=\frac{\text { bulk density }}{\text { full density }}
$$

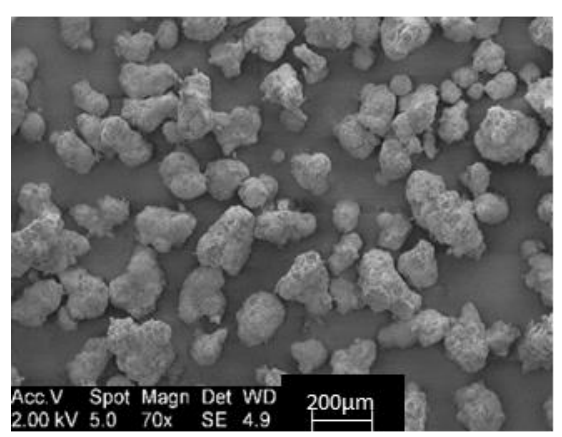

(a)

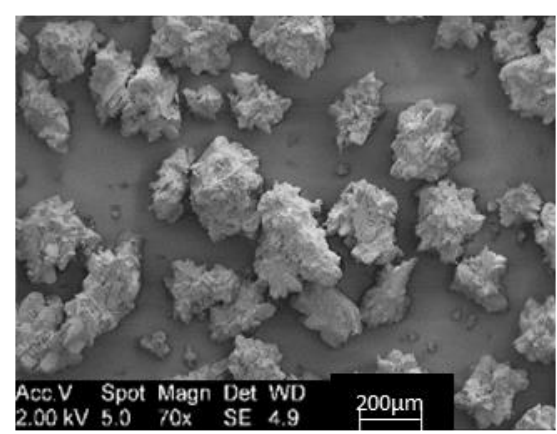

(b)

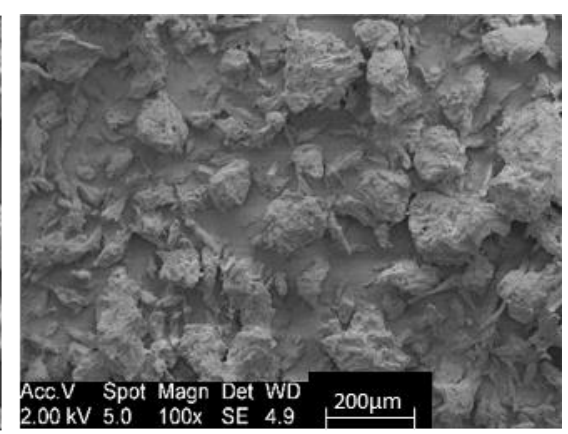

(c)

Figure 2. SEM images of (a) mannitol, (b) A-Tab, (c) MCC.

Table 1. Full and bulk densities of materials used in the experiments ( ${ }^{1}$ Rowe et al., 2009; 2Shang, 2012 and ${ }^{3}$ Baserinia, 2016). *indicate values calculated using the rule of mixtures

\begin{tabular}{|c|c|c|c|}
\hline Material & $\begin{array}{c}\text { Full density } \\
\left(\mathrm{kg} / \mathrm{m}^{3}\right)\end{array}$ & $\begin{array}{c}\text { Bulk density } \\
\left(\mathrm{kg} / \mathrm{m}^{3}\right)\end{array}$ & $R D_{\text {initial }}$ \\
\hline Mannitol & $1514^{1}$ & $498^{3}$ & 0.329 \\
\hline Calcium phosphate & $2890^{1}$ & $725^{3}$ & 0.251 \\
\hline Microcrystalline cellulose & $1590^{2}$ & $318^{3}$ & 0.2 \\
\hline Mannitol 50\%+Microcrystalline cellulose 50\% & $1551^{*}$ & $388^{*}$ & 0.25 \\
\hline Mannitol 50\% + Calcium phosphate 50\% & $1987^{*}$ & $590^{*}$ & 0.297 \\
\hline Mannitol 99\% + Magnesium stearate 1\% & $1514^{*}$ & $498^{*}$ & 0.329 \\
\hline Mannitol 99.5\% + Magnesium stearate 0.5\% & $1514^{*}$ & $498^{*}$ & 0.329 \\
\hline
\end{tabular}




\section{Experimental methods}

Tensile and compressive strength measurements were carried out using the diametrical compression and uniaxial compression testing, respectively. The diametrical compression method was used to determine the break force of the tablets. For each test samples of different densities were made using die compaction of powders. The specimen preparation and testing methods are described below.

\subsection{Manufacturing of tall cylindrical specimens for uniaxial compression}

Uniaxial compression tests require samples having a length to diameter ratio larger than 2:1. (Baker, 1978; Darvell, 1990) or 2.5 (Newman, 1964).

The specimens were compressed in a die of $12.5 \mathrm{~mm}$ diameter and $100 \mathrm{~mm}$ height as shown in Error! Reference source not found.Figure 3a. The load was applied using an MTS 810 material testing system manufactured by MTS, USA illustrated in Error! Reference source not found.Figure 3b. In order to reduce the friction effect between the die wall and powder to obtain homogeneous compacts, magnesium stearate was used to pre-lubricate the die following the procedure developed by Shang et al. (2013a). The compaction procedure consists of applying a loading rate of $10 \mathrm{~mm} / \mathrm{min}$ until the prescribed compaction pressure (in the range of $15-400 \mathrm{MPa}$ ) was reached. Finally, the specimen was ejected from the die, resulting in the compacts shown in Figure $3 \mathrm{c}$.

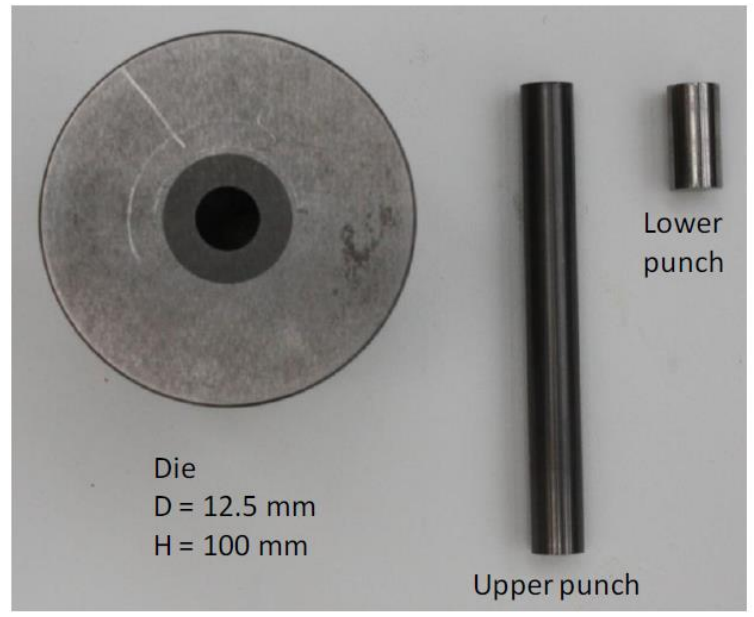

(a)

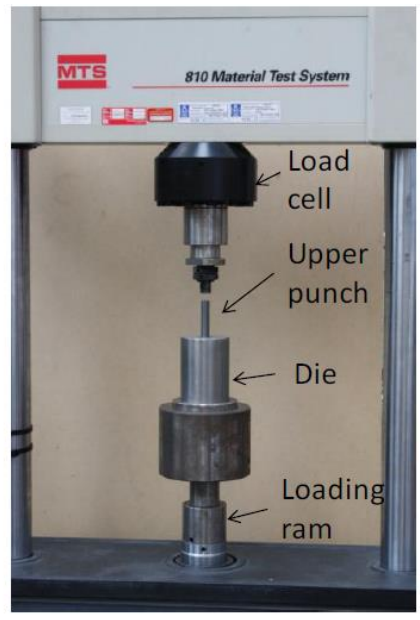

(b)

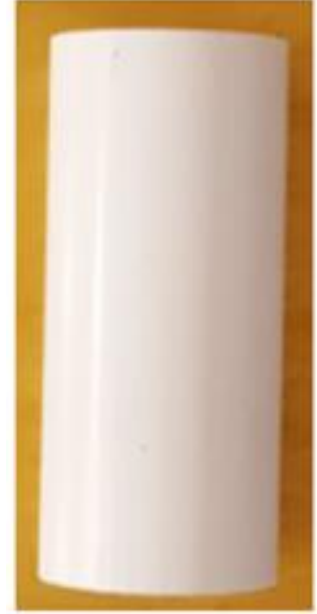

(c)

Figure 3: Tooling to manufacture tall cylinders specimens for uniaxial compression testing: (a) Die, upper and lower punches, (b) system set-up (Shang et al., 2013a) (c) typical compact, diameter 12.5 $\mathrm{mm}$, height $25 \mathrm{~mm}$.

\subsection{Manufacturing of tablets with flat and curved faces for diametrical compression}

Flat faced tablets have been manufactured using a die of $11 \mathrm{~mm}$ diameter and a height of $22.2 \mathrm{~mm}$ using flat faced punches as shown in Error! Reference source not found.Figure 4a. To produce the curved-face tablets with geometric features illustrated in Figure 4c, a die of $10.318 \mathrm{~mm}$ diameter 
was used with five sets of punches of various curvature (shallow, standard, deep, extra deep and ball). The radius of these curvatures are listed in Table 2 .

Before compression the upper punch was set to the level of the top surface of the die using a calibrated spacer. This step is important to record the top punch position correctly with respect to the die and the lower punch. Similar to the compression of tall cylindrical specimens, the die and punches were pre-lubricated with magnesium stearate to reduce the friction between powder and die wall. The loading rate was set to $10 \mathrm{~mm} / \mathrm{min}$ to compact the material until the prescribed compaction pressure was reached. Finally, the tablet was ejected from the die. Three different weights of tablets (200, 300 and $400 \mathrm{mg}$ ) were produced using ten different compaction pressures $(25,50,75,100,150,200,250,300,350$ and $400 \mathrm{MPa})$ defined as the top punch force divided by the area of the die cross-section. The flat faced discs were manufactured with a maximum thickness of $2.75 \mathrm{~mm}$; to comply with the thin disk assumption of the Hertz solution and the requirement that the aspect ratio of the tablet should not exceed $t / D \leq 0.25$ discussed in the introduction.

Table 2: Shapes of tablets (radius of tablet illustrated in Figure 1c).

\begin{tabular}{|c|c|c|c|c|c|}
\hline Punch shape & Shallow & Standard & Deep & Extra deep & Ball \\
\hline $\mathrm{R}(\mathrm{mm})$ & 30.12 & 13.869 & 10.44 & 7.514 & 5.599 \\
\hline
\end{tabular}

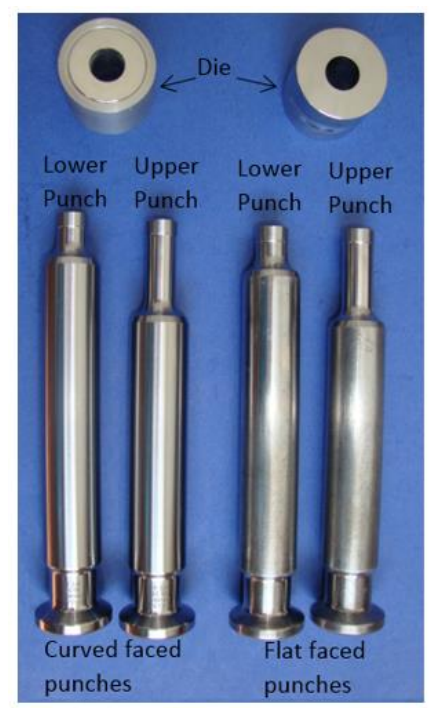

(a)

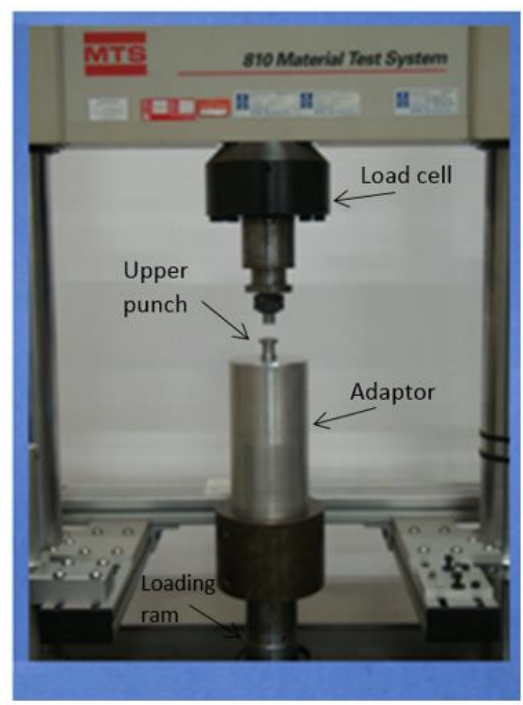

(b)

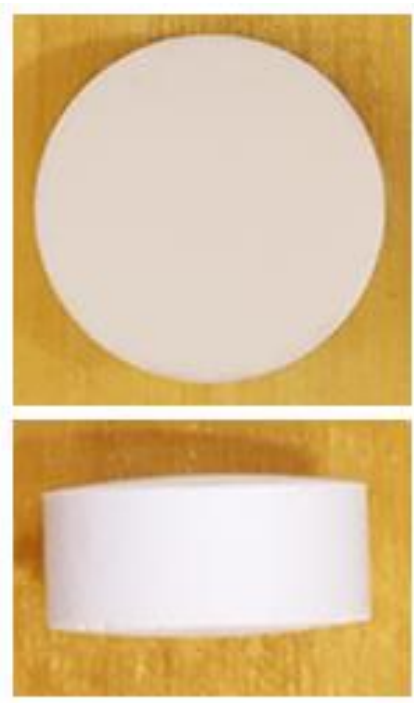

(c)

Figure 4. Tooling for manufacturing flat discs and curved faced tablets: (a) Die and upper and lower curved and flat faced punches, (b) system set-up, (c) typical flat and curved faced tablets

The experimental design for manufacturing the curved faced tablets is presented in detail as follows. The parameter space for curved faced tablets is defined by the dimensions of tablet shape, tablet weight and compaction pressure. The parameter combinations considered are listed in Tables 3-5 for mannitol, calcium phosphate, and microcrystalline cellulose, respectively.

A tick is used to indicate indicated that a tablet was produced for the corresponding parameter combination, and a cross indicates that no tablet was manufactured. For certain combinations tablets could not be produced because of the risk of punch damage should the two curved punches 
come into contact, for example low tablet mass, deep punch curvature and high compaction pressure.

For each individual punch curvature and weight, the test was repeated at least three times.

Table 3. Curved-face tablets experimental design for mannitol.

\begin{tabular}{|c|c|c|c|c|c|c|c|c|c|c|c|}
\hline \multirow{2}{*}{$\begin{array}{l}\text { Punch } \\
\text { shape }\end{array}$} & \multirow{2}{*}{$\begin{array}{l}\text { Weight } \\
\text { (mg) }\end{array}$} & \multicolumn{10}{|c|}{ Compaction Pressure (MPa) } \\
\hline & & 25 & 50 & 75 & 100 & 150 & 200 & 250 & 300 & 350 & 400 \\
\hline \multirow{3}{*}{ Shallow } & 400 & $\bar{\checkmark}$ & 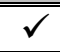 & $\sqrt{ } \checkmark$ & $\checkmark$ & $\bar{\checkmark}$ & $\checkmark$ & $\bar{\checkmark}$ & $\checkmark$ & $\checkmark \checkmark$ & $\bar{\checkmark}$ \\
\hline & 300 & $\checkmark$ & $\checkmark$ & $\checkmark$ & $\checkmark$ & $\checkmark$ & $\checkmark$ & $\checkmark$ & $\checkmark$ & $\checkmark$ & $\checkmark$ \\
\hline & 200 & $\checkmark$ & $\checkmark$ & $\checkmark$ & $\checkmark$ & $\checkmark$ & $\checkmark$ & $\checkmark$ & $x$ & $x$ & $x$ \\
\hline \multirow{3}{*}{ Standard } & 400 & $\checkmark$ & $\checkmark$ & $\checkmark$ & $\checkmark$ & $\checkmark$ & $\checkmark$ & $\checkmark$ & $\bar{\nabla}$ & $\bar{c}$ & $\bar{\nabla}$ \\
\hline & 300 & $\checkmark$ & $\checkmark$ & $\checkmark$ & $\checkmark$ & $\checkmark$ & $\checkmark$ & $\checkmark$ & $\checkmark$ & $\checkmark$ & $\checkmark$ \\
\hline & 200 & $\checkmark$ & $\checkmark$ & $\checkmark$ & $\checkmark$ & $x$ & $x$ & $x$ & $x$ & $x$ & $x$ \\
\hline \multirow{3}{*}{ Deep } & 400 & $\bar{\checkmark}$ & $\bar{\checkmark}$ & $\bar{\checkmark}$ & $\checkmark$ & $\bar{\checkmark}$ & $\bar{\checkmark}$ & $\bar{\checkmark}$ & $\bar{\checkmark}$ & 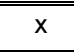 & 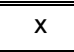 \\
\hline & 300 & $\checkmark$ & $\checkmark$ & $\checkmark$ & $\checkmark$ & $\checkmark$ & $\checkmark$ & $\checkmark$ & $x$ & $x$ & $x$ \\
\hline & 200 & $\checkmark$ & $\checkmark$ & $x$ & $x$ & $x$ & $x$ & $x$ & $x$ & $x$ & $x$ \\
\hline \multirow{3}{*}{$\begin{array}{l}\text { Extra } \\
\text { deep }\end{array}$} & 400 & $\checkmark$ & $\checkmark$ & $\bar{\checkmark}$ & $\checkmark$ & $\checkmark$ & $\checkmark$ & $x$ & $x$ & $x$ & $x$ \\
\hline & 300 & $\checkmark$ & $\checkmark$ & $\checkmark$ & $\checkmark$ & $x$ & $x$ & $x$ & $x$ & $x$ & $x$ \\
\hline & 200 & $x$ & $x$ & $x$ & $x$ & $x$ & $x$ & $x$ & $x$ & $x$ & $x$ \\
\hline \multirow{3}{*}{ Ball } & 400 & $\checkmark$ & $\sqrt{V^{*}}$ & $\bar{x}$ & $\bar{x}$ & 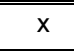 & $x$ & $x$ & $x$ & $x$ & $x$ \\
\hline & 300 & $x$ & $\mathrm{x}$ & $x$ & $x$ & $x$ & $x$ & $x$ & $x$ & $x$ & $x$ \\
\hline & 200 & $x$ & $x$ & $x$ & $x$ & $x$ & $x$ & $x$ & $x$ & $x$ & $x$ \\
\hline
\end{tabular}

* the mass of this tablet was $500 \mathrm{mg}$

Table 4. Curved-face tablets experimental design for calcium phosphate.

\begin{tabular}{|c|c|c|c|c|c|c|c|c|c|c|c|}
\hline \multirow{2}{*}{$\begin{array}{l}\text { Punch } \\
\text { shape }\end{array}$} & \multirow{2}{*}{$\begin{array}{c}\text { Weight } \\
\text { (mg) }\end{array}$} & \multicolumn{10}{|c|}{ Compaction Pressure (MPa) } \\
\hline & & 25 & 50 & 75 & 100 & 150 & 200 & 250 & 300 & 350 & 400 \\
\hline \multirow{3}{*}{ Shallow } & 400 & $\sqrt{ }$ & $\checkmark$ & $\checkmark$ & $\checkmark$ & $\checkmark$ & $\checkmark$ & $\checkmark$ & $\checkmark$ & $\checkmark$ & $\checkmark$ \\
\hline & 300 & $\mathrm{x}$ & $\checkmark$ & $\checkmark$ & $\checkmark$ & $\checkmark$ & $\checkmark$ & $\checkmark$ & $\checkmark$ & $\mathrm{x}$ & $\mathrm{x}$ \\
\hline & 200 & $\mathrm{x}$ & $\mathrm{x}$ & $\mathrm{x}$ & $\mathrm{x}$ & $\mathrm{x}$ & $\mathrm{x}$ & $\mathrm{x}$ & $\mathrm{x}$ & $\mathrm{x}$ & $\mathrm{x}$ \\
\hline \multirow{3}{*}{ Standard } & 400 & $\bar{\checkmark}$ & $\bar{\checkmark}$ & $\overline{\bar{\checkmark}}$ & $\bar{\checkmark}$ & $\overline{\bar{\checkmark}}$ & $\overline{\bar{\checkmark}}$ & $\bar{\checkmark}$ & $\bar{\checkmark}$ & $\bar{\checkmark}$ & $\overline{\bar{\checkmark}}$ \\
\hline & 300 & $x$ & $\checkmark$ & $\checkmark$ & $\checkmark$ & $\checkmark$ & $x$ & $x$ & $x$ & $x$ & $x$ \\
\hline & 200 & $\mathrm{x}$ & $x$ & $\mathrm{x}$ & $x$ & $x$ & $x$ & $\mathrm{x}$ & $x$ & $x$ & $x$ \\
\hline \multirow{3}{*}{ Deep } & 400 & $\checkmark$ & $\checkmark$ & $\checkmark$ & $\checkmark$ & $\checkmark$ & $\bar{v}$ & $\checkmark$ & $\bar{x}$ & $\bar{x}$ & $x$ \\
\hline & 300 & $x$ & $\checkmark$ & $x$ & $x$ & $x$ & $x$ & $x$ & $x$ & $x$ & $x$ \\
\hline & 200 & $x$ & $x$ & $x$ & $x$ & $x$ & $x$ & $x$ & $x$ & $x$ & $x$ \\
\hline \multirow{3}{*}{$\begin{array}{l}\text { Extra } \\
\text { deep }\end{array}$} & 4400 & $\checkmark$ & $\bar{\checkmark}$ & $\bar{x}$ & $\bar{x}$ & $\bar{x}$ & $\bar{x}$ & $\begin{array}{c}x \\
\end{array}$ & $\bar{x}$ & $\bar{x}$ & $\begin{array}{l}x \\
\end{array}$ \\
\hline & 300 & $x$ & $x$ & $x$ & $x$ & $x$ & $x$ & $x$ & $x$ & $x$ & $x$ \\
\hline & 200 & $x$ & $x$ & $x$ & $x$ & $x$ & $x$ & $x$ & $x$ & $x$ & $x$ \\
\hline \multirow{3}{*}{ Ball } & 400 & $\bar{x}$ & $x$ & $x$ & $\bar{x}$ & $x$ & $x$ & $x$ & $\bar{x}$ & $x$ & $x$ \\
\hline & 300 & $x$ & $x$ & $x$ & $x$ & $x$ & $x$ & $x$ & $x$ & $x$ & $x$ \\
\hline & 200 & $x$ & $x$ & $x$ & $x$ & $x$ & $x$ & $x$ & $x$ & $x$ & $x$ \\
\hline
\end{tabular}


Table 5. Curved-face tablets experimental design for microcrystalline cellulose.

\begin{tabular}{|c|c|c|c|c|c|c|c|c|c|c|c|}
\hline \multirow{2}{*}{$\begin{array}{l}\text { Punch } \\
\text { shape }\end{array}$} & \multirow{2}{*}{$\begin{array}{l}\text { Weight } \\
\text { (mg) }\end{array}$} & \multicolumn{10}{|c|}{ Compaction Pressure (MPa) } \\
\hline & & 25 & 50 & 75 & 100 & 150 & 200 & 250 & 300 & 350 & 400 \\
\hline \multirow{3}{*}{ Shallow } & 400 & $\bar{\checkmark}$ & $\bar{\checkmark}$ & $\bar{\checkmark}$ & $\bar{\checkmark}$ & $\bar{\checkmark}$ & $\bar{\checkmark}$ & $\bar{\checkmark}$ & $\bar{\checkmark}$ & $\bar{\checkmark}$ & $\bar{\checkmark}$ \\
\hline & 300 & $\checkmark$ & $\checkmark$ & $\checkmark$ & $\checkmark$ & $\checkmark$ & $\checkmark$ & $\checkmark$ & $\checkmark$ & $\checkmark$ & $\checkmark$ \\
\hline & 200 & $\checkmark$ & $\checkmark$ & $\checkmark$ & $\checkmark$ & $\checkmark$ & $\checkmark$ & $\checkmark$ & $\mathrm{x}$ & $x$ & $x$ \\
\hline \multirow{3}{*}{ Standard } & 400 & $\bar{\checkmark}$ & $\bar{v}$ & $\bar{\checkmark}$ & $\bar{v}$ & $\bar{v}$ & $\bar{v}$ & $\checkmark$ & $\bar{v}$ & $\bar{v}$ & $\bar{\checkmark}$ \\
\hline & 300 & $\checkmark$ & $\checkmark$ & $\checkmark$ & $\checkmark$ & $\checkmark$ & $\checkmark$ & $\checkmark$ & $\checkmark$ & $\checkmark$ & $\checkmark$ \\
\hline & 200 & $\checkmark$ & $\checkmark$ & $\checkmark$ & $x$ & $x$ & $x$ & $x$ & $x$ & $x$ & $x$ \\
\hline \multirow{3}{*}{ Deep } & 400 & $\checkmark$ & $\bar{\checkmark}$ & $\bar{\checkmark}$ & $\bar{\checkmark}$ & $\bar{\checkmark}$ & $\bar{\checkmark}$ & $\bar{v}$ & $\bar{\checkmark}$ & $\bar{\checkmark}$ & $\bar{\checkmark}$ \\
\hline & 300 & $\checkmark$ & $\checkmark$ & $\checkmark$ & $\checkmark$ & $\checkmark$ & $x$ & $x$ & $x$ & $x$ & $x$ \\
\hline & 200 & $\checkmark$ & $x$ & $x$ & $x$ & $x$ & $\mathrm{x}$ & $\mathrm{x}$ & $\mathrm{x}$ & $\mathrm{x}$ & $\mathrm{x}$ \\
\hline \multirow{3}{*}{ Extra deep } & 400 & $\bar{v}$ & $\checkmark$ & $\checkmark$ & $\checkmark$ & $\checkmark$ & $\bar{x}$ & $\bar{x}$ & $\bar{x}$ & $\bar{x}$ & $\bar{x}$ \\
\hline & 300 & $\checkmark$ & $\checkmark$ & $x$ & $x$ & $x$ & $x$ & $x$ & $x$ & $x$ & $x$ \\
\hline & 200 & $x$ & $x$ & $x$ & $x$ & $x$ & $x$ & $x$ & $x$ & $x$ & $x$ \\
\hline \multirow{3}{*}{ Ball } & 400 & $\overline{\bar{v}}$ & $\overline{V^{*}}$ & $\bar{x}$ & $\bar{x}$ & $\bar{x}$ & $\bar{x}$ & $\bar{x}$ & $\bar{x}$ & $\bar{x}$ & $\bar{x}$ \\
\hline & 300 & $x$ & $\mathrm{x}$ & $x$ & $x$ & $x$ & $x$ & $x$ & $x$ & $x$ & $x$ \\
\hline & 200 & $x$ & $x$ & $x$ & $x$ & $x$ & $x$ & $x$ & $x$ & $x$ & $x$ \\
\hline
\end{tabular}

* the mass of this tablet was $500 \mathrm{mg}$

Figures 5-7 show graphically the experiments that were carried out for the curved-face tablets by showing the ratio $W / D$ and $t / D$ for each tablet tested, for mannitol, calcium phosphate, and microcrystalline cellulose respectively. The dotted line indicates to the region of validity of Pitt's Equation 9. For flat faced tablets $W=t$; points corresponding to flat-faced tablet experiments are omitted from the tables for clarity. In Figures 6-7 tablets with the same curvature are represented by points lying on the same solid diagonal line. 


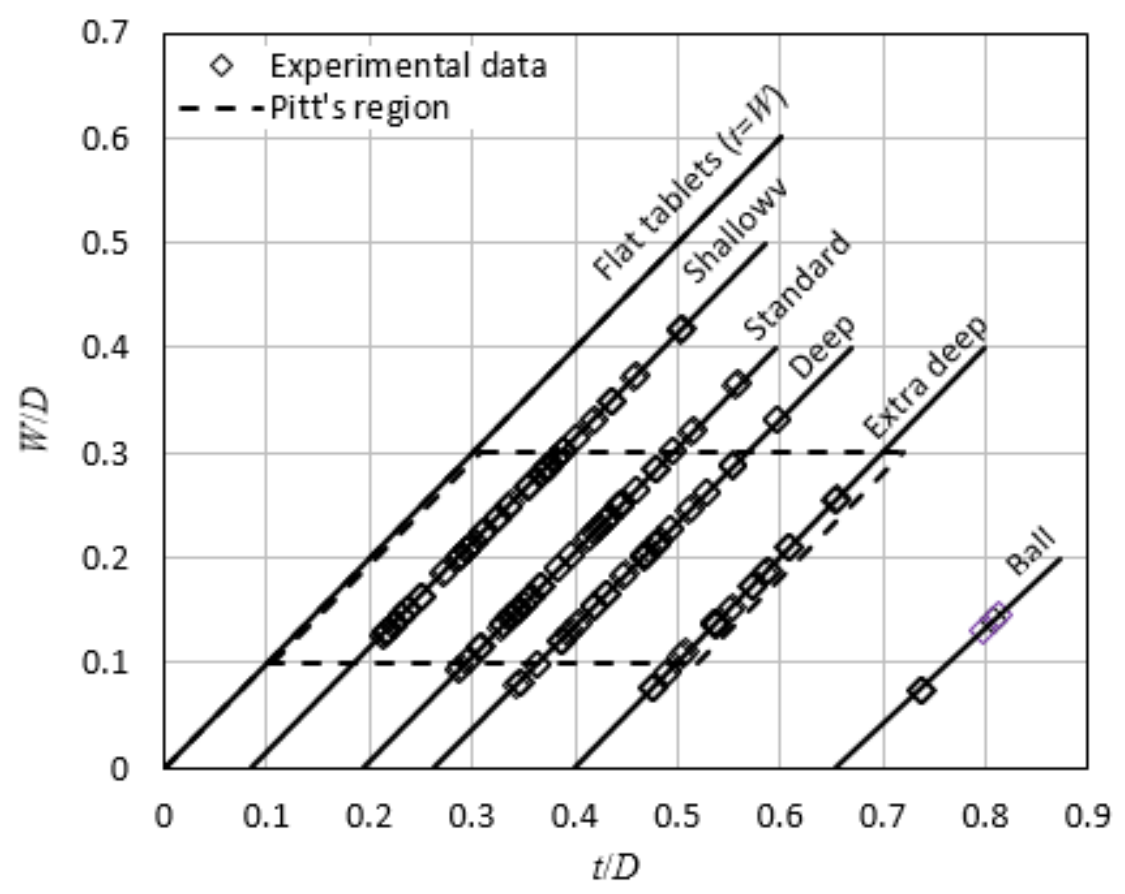

Figure 5. Experimental space detailing curved-face tablet geometry for mannitol.

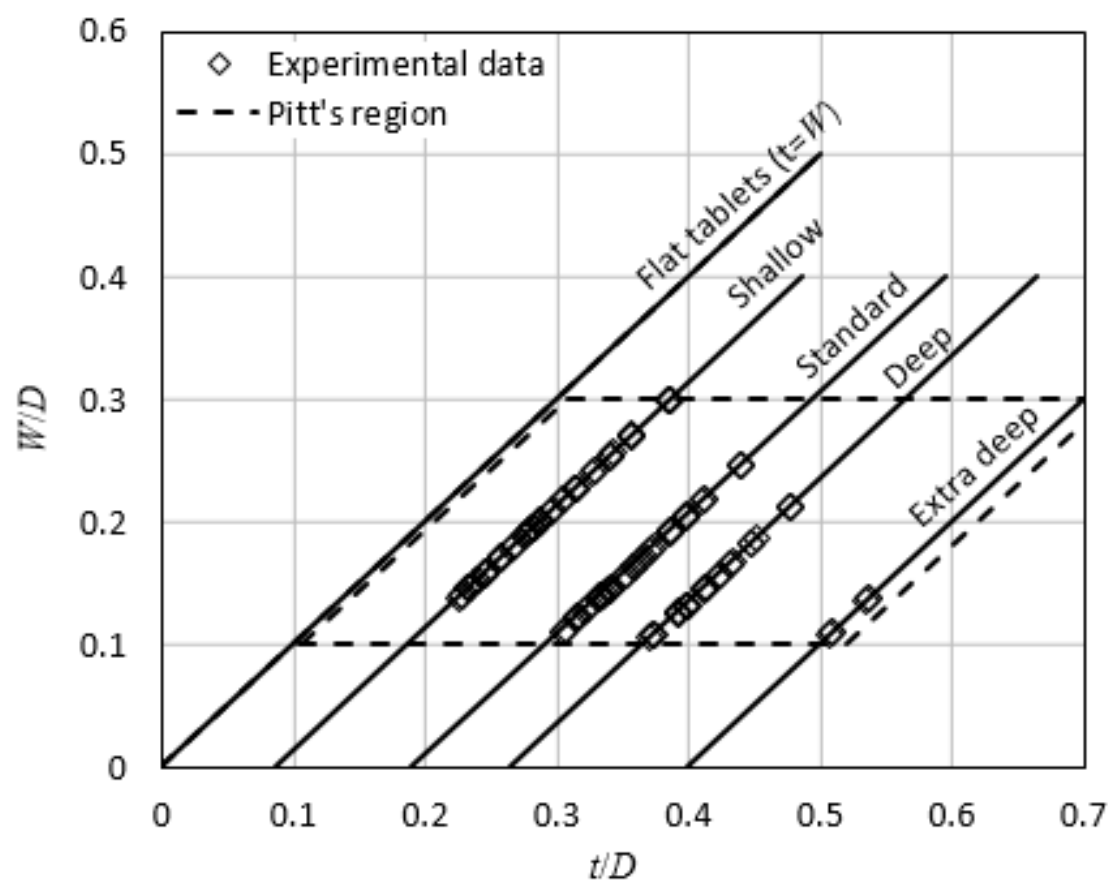

Figure 6. Experimental space detailing curved-face tablet geometry for calcium phosphate. 


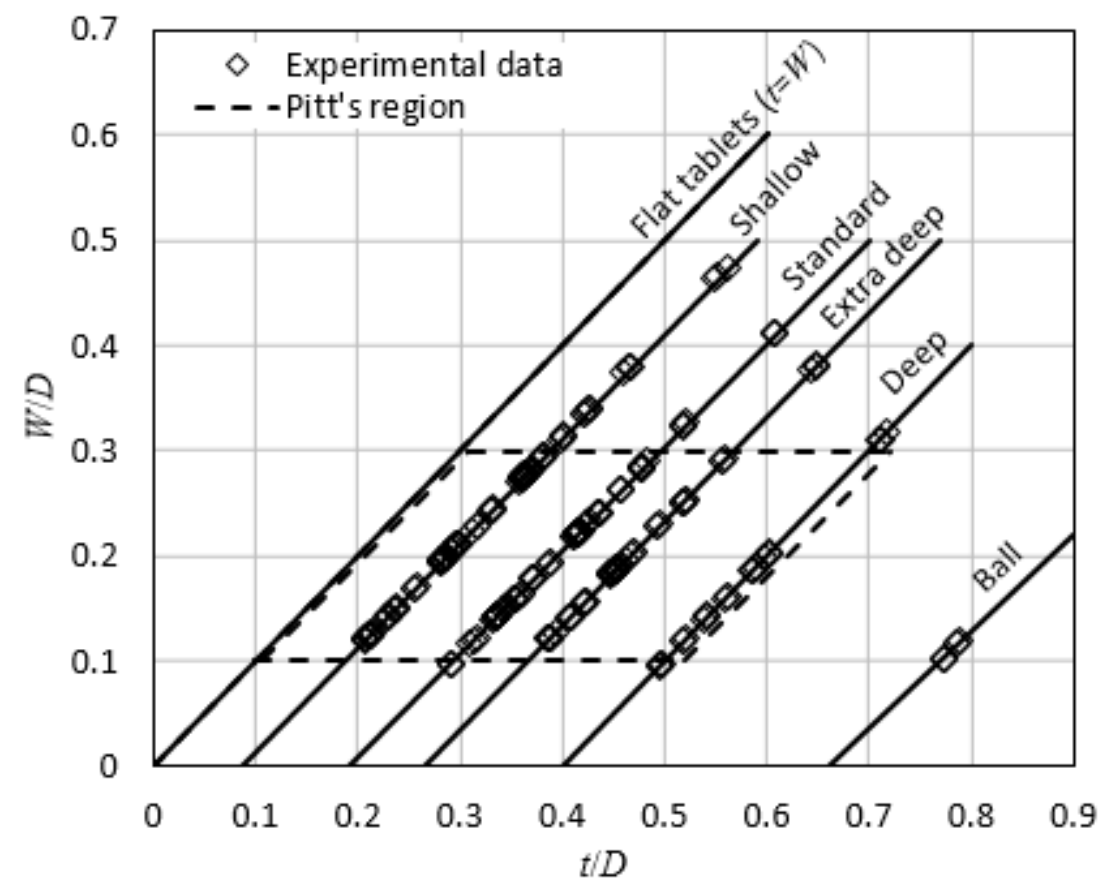

Figure 7. Experimental space detailing curved-face tablet geometry for microcrystalline cellulose.

\subsection{Compressive and tensile strength testing}

The procedure for diametrical and uniaxial compression testing is described as follows. The MTS 810 material testing system used to apply load at a rate of $1 \mathrm{~mm} / \mathrm{min}$ and $10 \mathrm{~mm} / \mathrm{min}$ for diametrical compression and uniaxial compression, respectively. Figure 8 shows typical specimens during testing.

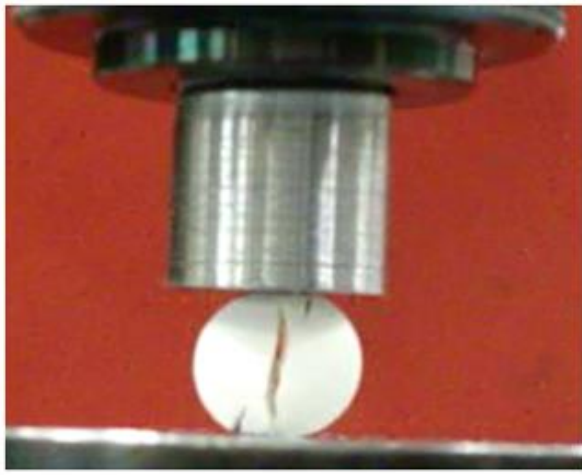

(a)

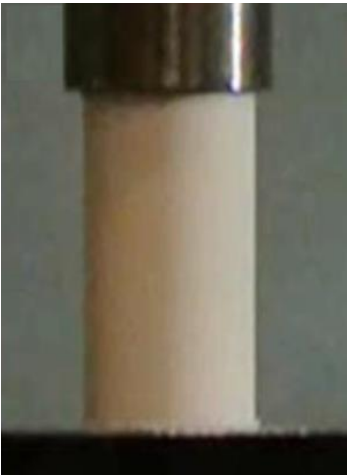

(b)

Figure 8. Strength testing of tablets: a) tablet subject to diametrical compression after failure b) tall cylinder under uniaxial compression

For flat faced disks under diametrical compression the tensile strength is calculated using Equation 4. For tall cylinders the uniaxial compressive strength $\left(\sigma_{u}\right)$ in determined as:

$$
\sigma_{u}=\frac{4 F_{u}}{\pi D^{2}}
$$


where $F_{u}$ is the break force under uniaxial compression and $D$ is the diameter of the cylinder.

\section{Results and discussion}

The compressive and tensile strength relationships with respect to relative density are presented for the three pure excipients and four mixtures in the sections below. The data are fitted with an empirical Equation 27 that has two parameters for each case (tension and compression).

$$
\sigma=c\left(R D-R D_{\text {initial }}\right)^{n}
$$

where $\mathrm{RD}$ and $R D_{\text {initial }}$ are the final and initial relative density, respectively. $R D_{\text {initial }}$ is calculated using Equation 25. It is noted that empirical stress-density equations have been introduced since the 1980s (Leuenberger 1982; Kuentz and Leuenberger 2000); however, these are not universally applicable for all types of powders and densities. By using two material dependent parameters, Equation 27 fits adequately the strength of the compacts as described below.

\subsection{Tensile strength of thin disks with flat faces}

Figure 9 shows the tensile strength obtained in the experiments, the continuous lines represent Equation 27 with fitting parameters $c_{d}$ and $n_{d}$ listed in Table 6 (the subscripts indicating diametrical compression). The results show that the tensile strength increases as the relative density increases; this is expected. 


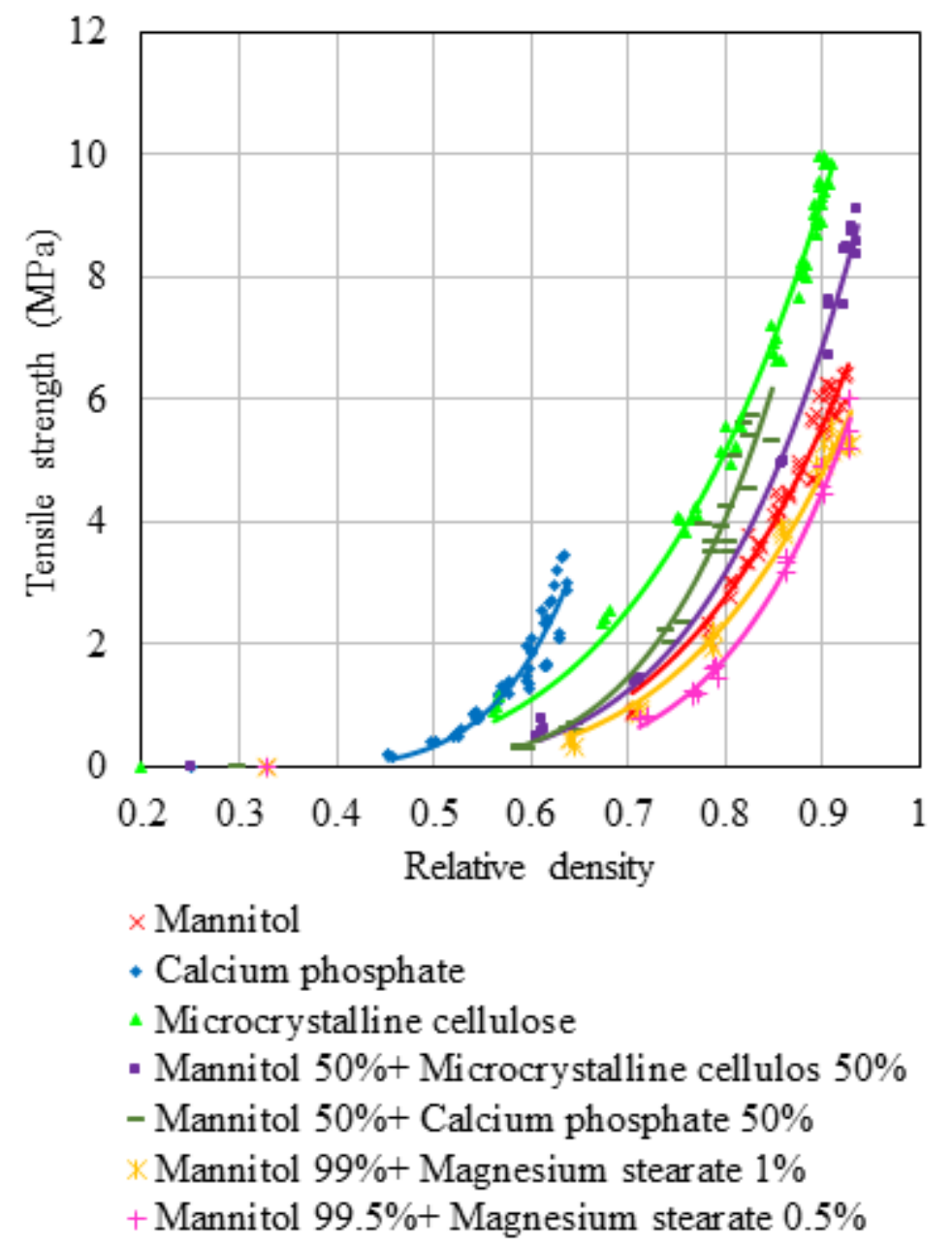

Figure 9. Tensile strength versus relative density.

Table 6. Values of fitting parameters $c_{d}$ and $n_{d}$.

\begin{tabular}{|c|c|c|}
\hline Material & $c_{d}(\mathrm{MPa})$ & $n_{d}$ \\
\hline Mannitol & 42.44 & 3.62 \\
\hline Calcium phosphate & 328.3 & 4.94 \\
\hline Microcrystalline cellulose & 36.1 & 3.81 \\
\hline Mannitol 50\% + Microcrystalline cellulose 50\% & 50.35 & 4.62 \\
\hline Mannitol 50\% + Calcium phosphate 50\% & 94.68 & 4.58 \\
\hline Mannitol 99\% + Magnesium stearate 1\% & 38.67 & 3.72 \\
\hline Mannitol 99.5\% + Magnesium stearate 0.5\% & 66.26 & 4.8 \\
\hline
\end{tabular}

\subsection{Uniaxial compressive strength}

The uniaxial strength data was analysed similarly and the values of the parameters obtained for the uniaxial compression tests, $c_{u}$ and $n_{u}$ are presented in Table 7. Figure 10 shows the compressive strengths obtained in the experiments. 


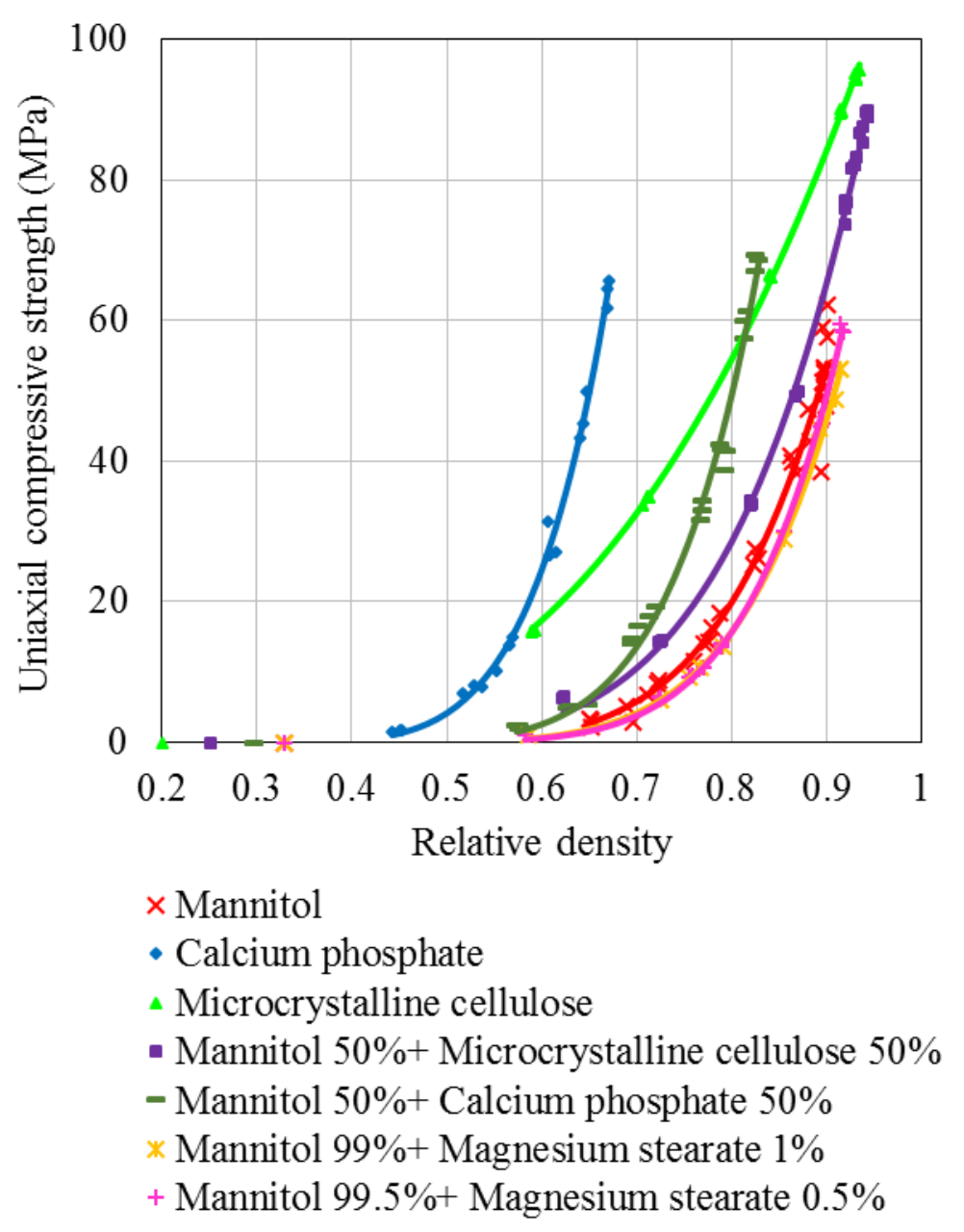

Figure 10. Uniaxial compressive strength versus relative density

Table 7. Values of fitting parameters $c_{u}$ and $n_{u}$.

\begin{tabular}{|c|c|c|}
\hline Material & $c_{u}(\mathrm{MPa})$ & $n_{u}$ \\
\hline Mannitol & 953.7 & 5.14 \\
\hline Calcium phosphate & 6264.8 & 5.27 \\
\hline Microcrystalline cellulose & 229.5 & 2.82 \\
\hline Mannitol 50\% + Microcrystalline cellulose 50\% & 550.5 & 4.95 \\
\hline Mannitol 50\% + Calcium phosphate 50\% & 2701.4 & 5.82 \\
\hline Mannitol 99\% + Magnesium stearate 1\% & 1033 & 5.56 \\
\hline Mannitol 99.5\% + Magnesium stearate 0.5\% & 1376.3 & 5.95 \\
\hline
\end{tabular}

Figures 9-10 can be used to compare the strength of different excipients as function of relative density. The magnitude of compressive strength is about an order of magnitude higher than the tensile strength and this not unexpected. The tensile and compressive strength data will be used to interpret the strength of curved faced tablet and develop a predictive model described below.

\subsection{Flat face tensile and compressive strength data}

Flat faced diametrical and compressive data are used to describe the shear failure as part of the constitutive model for Drucker Prager Cap surface. The parameters $c_{d}$ and $c_{u}$ obtained from tensile and compressive strength versus relative density behaviour (Equation 27) encode material 
properties of the three single component materials (Leuenberger (1982). Data in Tables 6 and 7 are indicative of the deformation behaviour of the material with MCC having the lowest values in the relative order of $\mathrm{MCC}<$ Mannitol< Dicalcium phosphate reflecting the order of the yield stress of the three materials and hence will be used to develop the predictive model described below.

\subsection{Break force of curved faced tablets}

The relationships between break force and tablet relative density for mannitol, calcium phosphate, and microcrystalline cellulose, respectively, are presented in Figures 11-13. These figures show the effect of tablet geometry on the break force. For the same relative density, tablets with larger thickness require higher break forces. Normalisation is thus required to develop relationships for practical use.

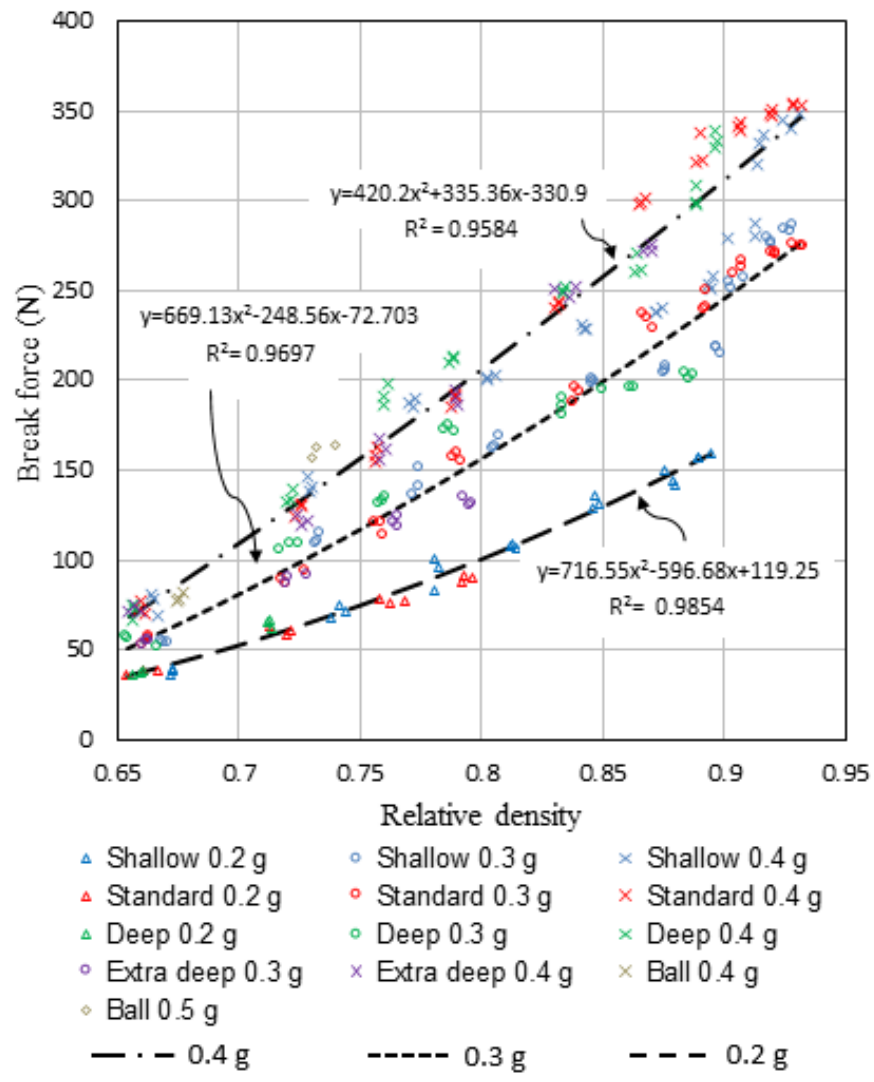

Figure 11. Effect of tablet mass on the break force for mannitol. The labels indicate tablet curvature (see Table 4-1) and the tablet mass. 


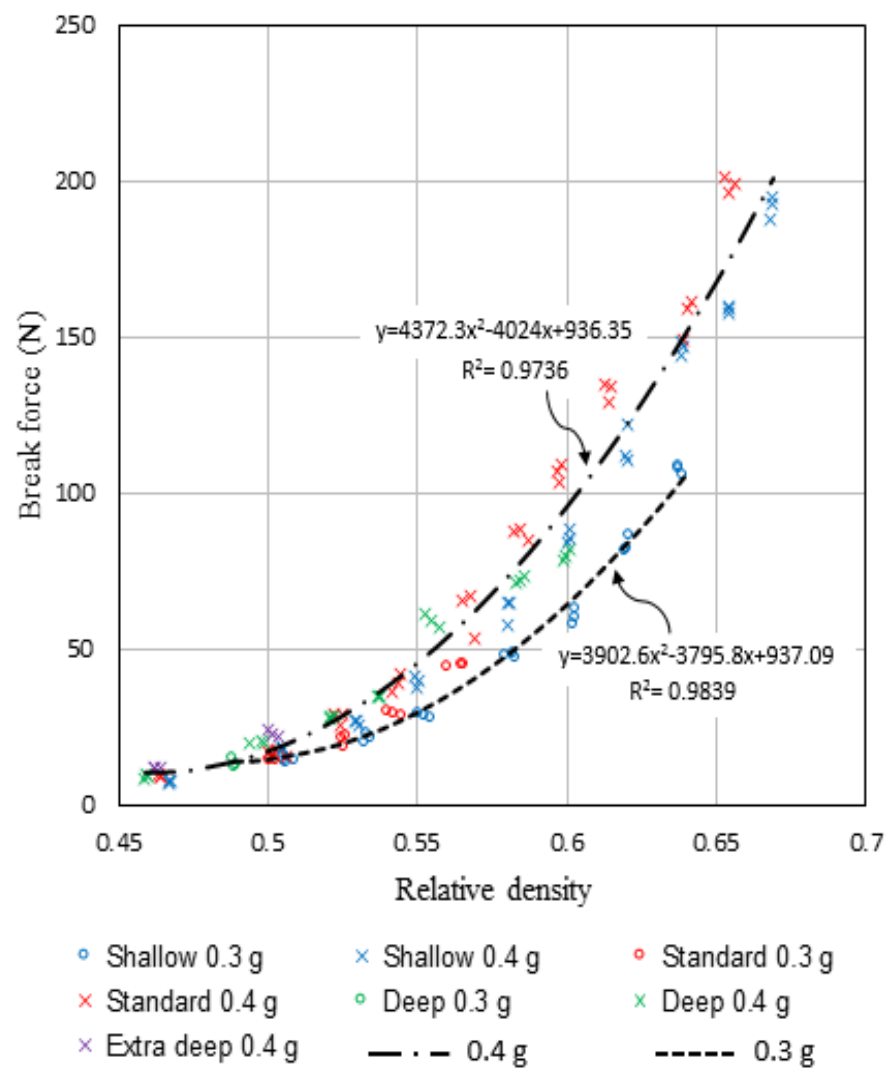

Figure 12 Effect of tablet mass on the break force break force for calcium phosphate. The labels indicate tablet curvature (see Table 2 ) and the tablet mass.

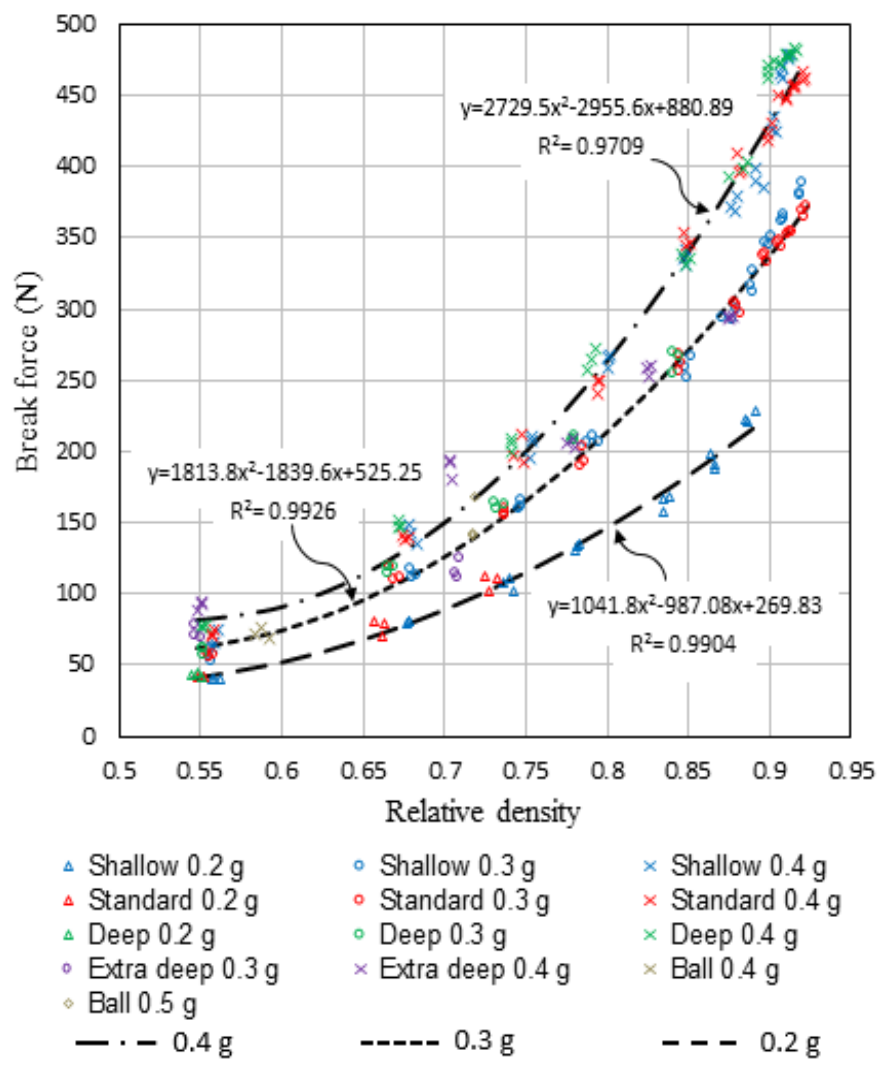

Figure 13. Effect of tablet mass on the break force for microcrystalline cellulose. The labels indicate tablet curvature (see Table 4-1) and the tablet mass. 
The procedure developed by Shang (2013) was applied and the empirical parameters $a$ and $b$ in Equation 16 were determined for the three pure excipients for which complete sets of data were available for the full range of punch curvatures (Table 2). The coefficients of Equation 16 are presented in Table 8 . The relative density of a curved faced tablet is given by its mass and geometry and its break force is measured. To fit the empirical parameters $a$ and $b$ to the experimental data using Equation 16, it is necessary to know the tensile strength of the material for that particular density; this information is taken from Figure 9.

Table 8. Coefficients of the two parameter model of Shang et al. obtained for full tablet data set (thin disks and curved faced tablets).

\begin{tabular}{|c|c|c|}
\hline Materials & $a$ & $b$ \\
\hline Mannitol & 0.358 & 0.142 \\
\hline Calcium phosphate & 0.349 & 0.151 \\
\hline Microcrystalline cellulose & 0.245 & 0.255 \\
\hline
\end{tabular}

Using the values in Table 8 Equation 16 is plotted in Figure 14 illustrating the normalised break force as a function of geometric features $W / D$ and $t / D$ for the three pure excipients. The tensile strength $\sigma_{d}$ was taken from Figure 9 .

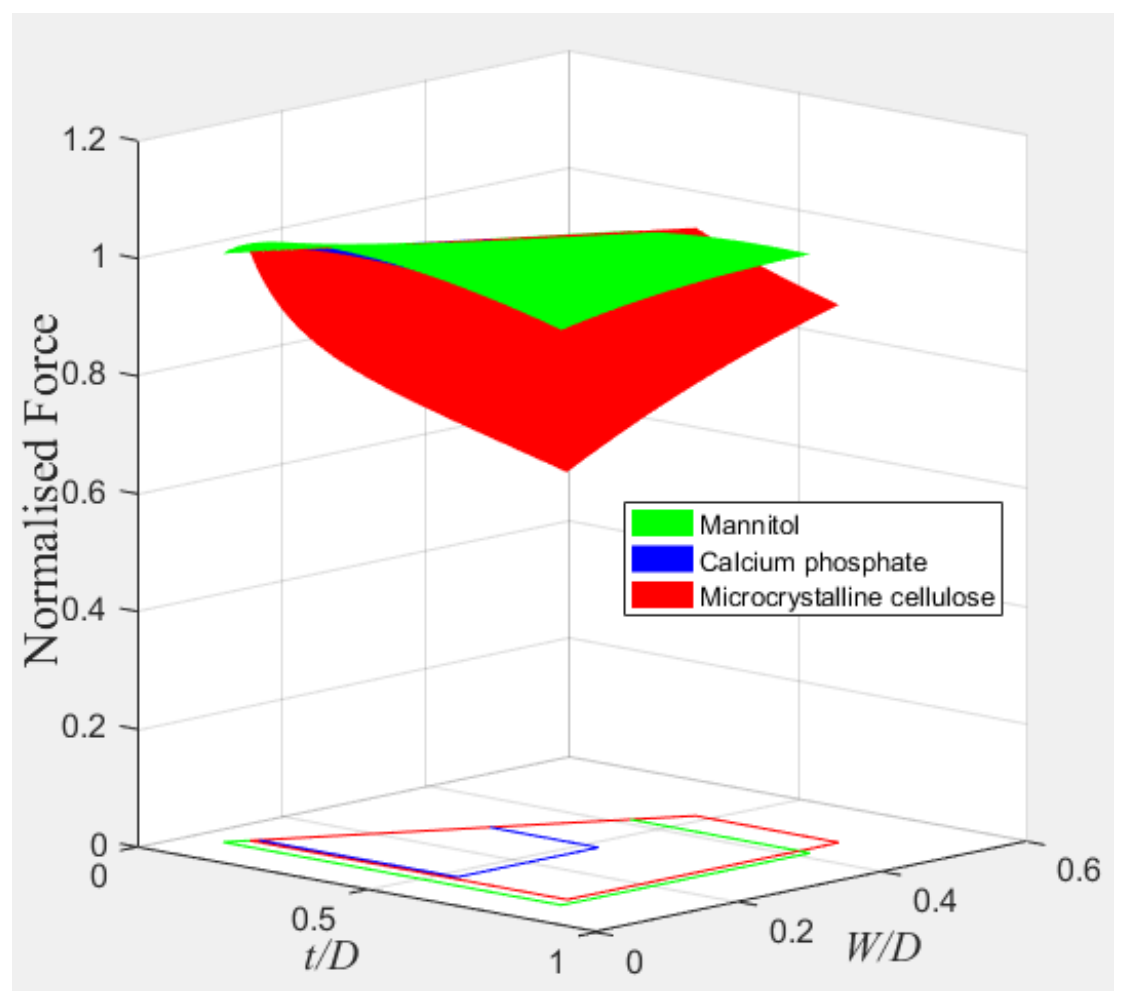

Figure 14 Comparison between the normalised break force of mannitol, calcium phosphate, and microcrystalline cellulose.

The surfaces of normalised force for mannitol and calcium phosphate are relatively similar and the parameters in Table 8 are relatively close. An analysis of errors between the actual break force of curved faced tablet and the values presented by Equation 16 is presented following further model refinement. 


\subsection{Failure model of curved faced tablets}

The failure behaviour of tablets of various shapes is examined below. According to Hertz a uniform state of a tensile stress is developed in a thin elastic flat disks subjected to a load across its diameter. Such loading leads to a characteristic brittle splitting failure mode shown in photographs labelled (a) in Figures 15-17 for the three pure excipients. For curved-face tablets, more complex failure modes are observed which are indicated with filled symbols.

Failure patterns obtained in the experiments for curved-face mannitol tablets in Figure 15b,e (deep and extra-deep tablets) show full delamination. Figure $15 \mathrm{c}, \mathrm{d}, \mathrm{f}, \mathrm{g}$ (deep, extra-deep and ball tablets) show a more complicated pattern, where a primary crack occurs due to tensile stress followed by a crack across the band width, except (f), which present shattering behaviour.

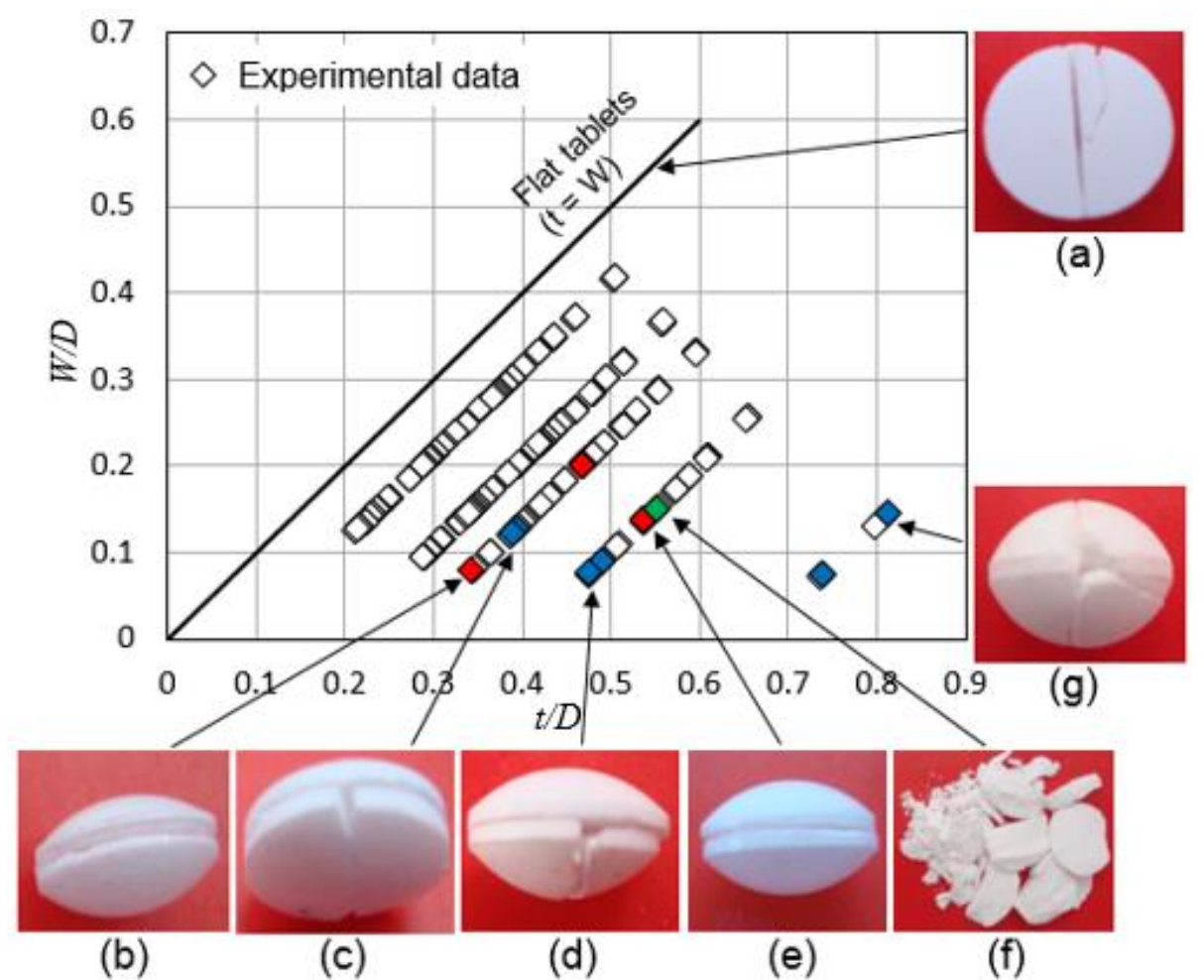

Figure 15. Complex failure mechanisms of mannitol tablets. Solid red symbols indicate full delamination. Solid blue symbols indicate both delamination and breaking into halves. Photos (b-g) to (g) show tablets compacted under pressures of 50, 200, 75, 200, 150 and $50 \mathrm{MPa}$, using powder weights 200, 300, 300, 400, 400 and 400mg, respectively.

For calcium phosphate, tablets with deep curvature showed a more complex failure pattern, as shown in Figure 16b. Some tablets with deep curvature displayed full delamination, as shown in Figure 16c.

In the case of microcrystalline cellulose tablets, tablet with, standard, deep, and extra deep curvatures showed both full delamination and complexity, as shown in Figure $17 \mathrm{~b}, \mathrm{~d}, \mathrm{f}$, and Figure $17 c, e, g$, respectively. Ball shaped tablets display fully delamination, as shown in Figure $17 \mathrm{~h}$. 


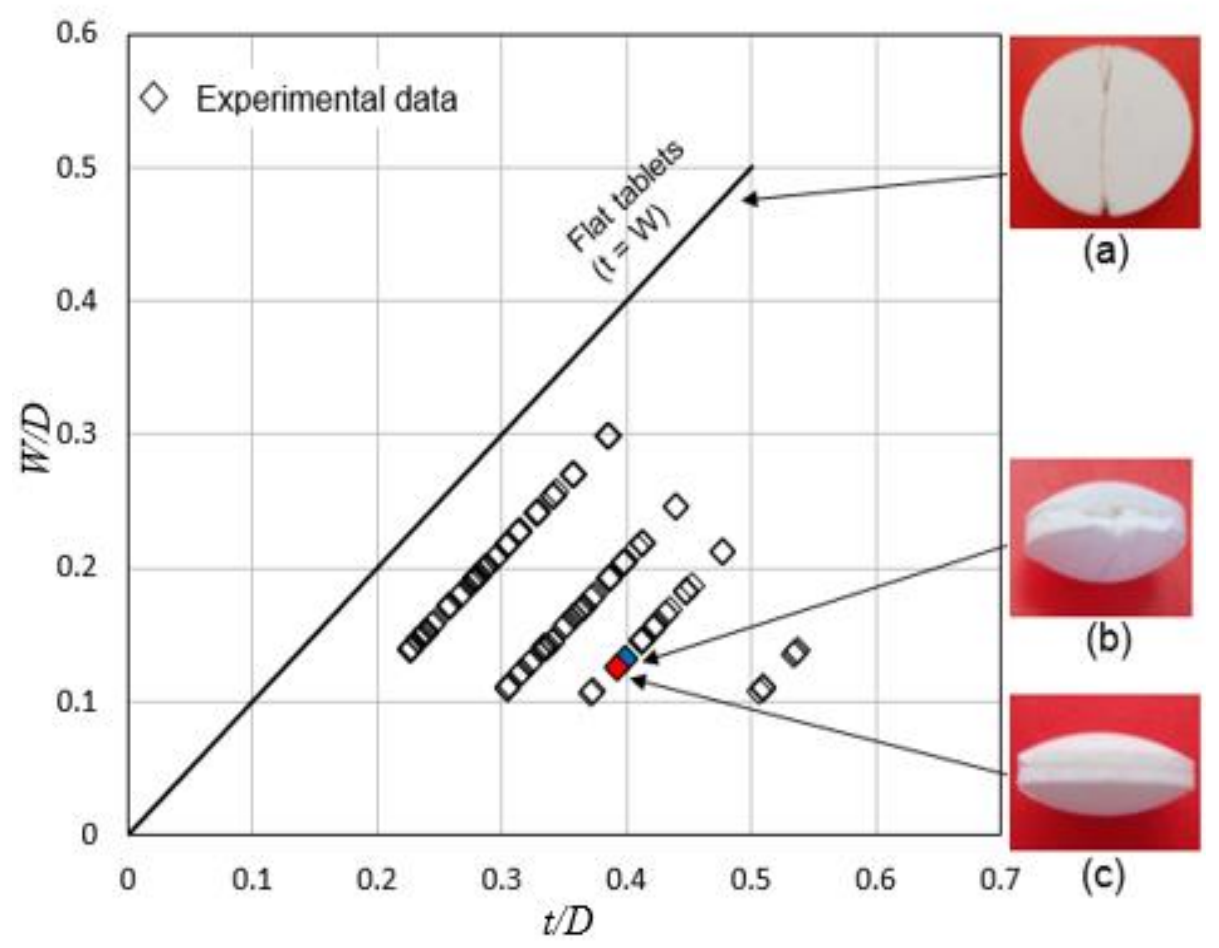

Figure 16. Complex failure mechanisms of calcium phosphate tablets. A solid red symbol indicates tablets showing full delamination. A solid blue symbol indicates tablets which exhibit both delamination and breaking into two halves. Photos (b-c) show tablets which were compacted under pressures of 250 and $200 \mathrm{MPa}$, using powder weights of 400 and $400 \mathrm{mg}$, respectively.

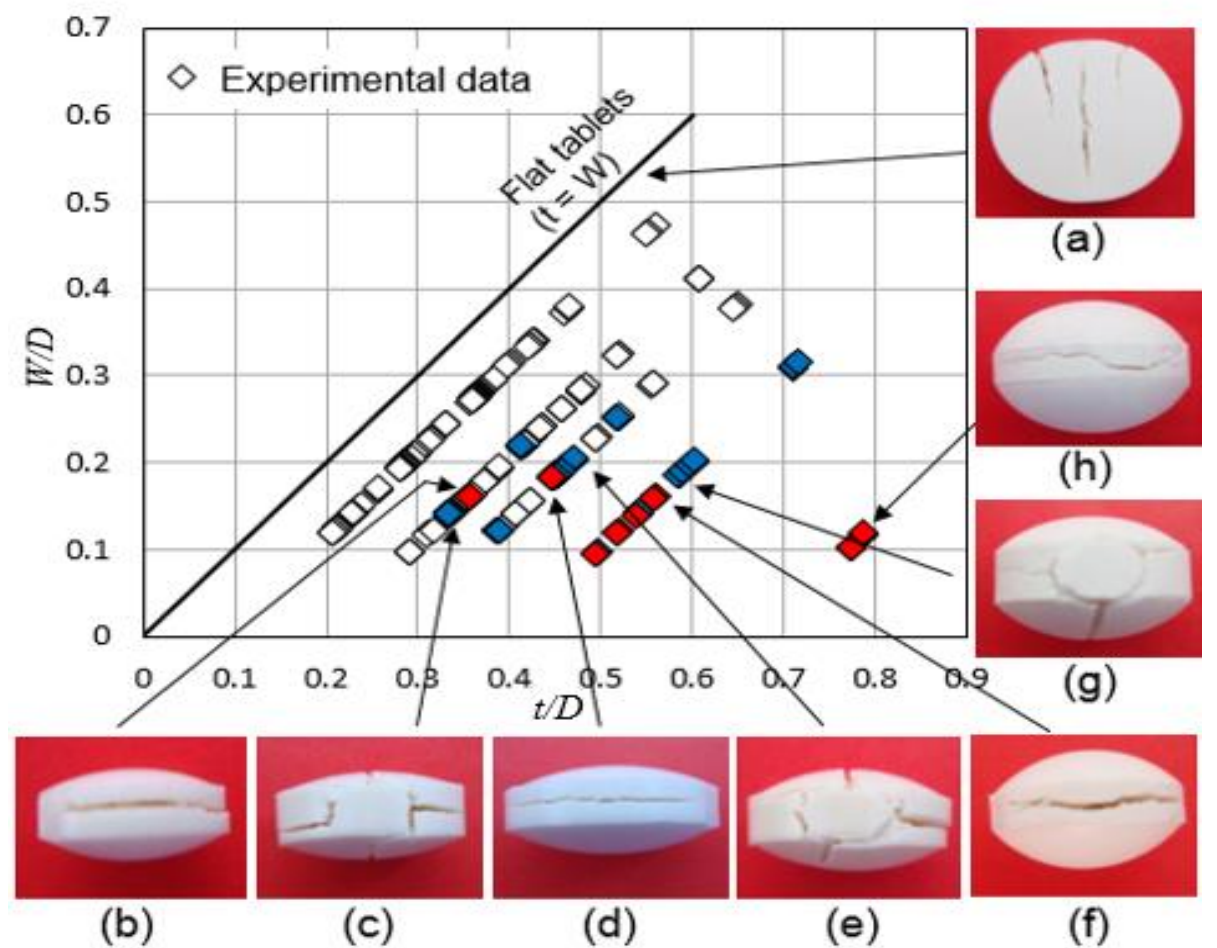

Figure 17. Complex failure mechanism of microcrystalline cellulose tablets. Solid red symbols indicate tablets which fully delaminate. Solid blue symbols indicate tablets which exhibit both delamination and breaking into two halves. Photos $(b-h)$ show tablets which were compacted under pressures of 350, 300, 350, 200, 75, 50 and $25 \mathrm{MPa}$, using powder weights $300,300,400,400,400$, 400 and $400 \mathrm{mg}$, respectively. 
The failure patterns shown by the tablets arise due to complex mechanisms with multiple causes including material inhomogeneity, stress state, and defects:

- Material inhomogeneity or internal density distributions within tablets (discussed in the introduction) affect the break force and failure pattern of tablets of identical size and weight (Sinka et al. 2004b).

- The stress state in tablets having high thickness deviate from Hertz's solution for a thin elastic disk, and together with the potential non-homogeneity, can lead to complex failure modes.

- Pitt et al. (1989a) and Haririan and Newton (1999) suggested that inherent defects give rise to variation in observed patterns of failure. Delamination in tablets were found by Wu et al. (2008) using X-ray computed tomography. These flaws with its distribution are assumed to have a significant influence on tablet strength. More recently, Mazel et al. (2018) identified experimentally the existence of internal cracks at the centre of biconvex tablets normal to the band area and have concluded based on FEA that such cracks are induced by tensile stresses due to the residual die wall stress following compaction. Pre-existing cracks may therefore be responsible for some of the failure modes presented in Figures 15-17.

In the following analysis the tablets exhibiting complex failure modes are ignored. The fitting procedure is repeated to obtain new parameters $a$ and $b$ shown in Table 9. The new surfaces are replotted in Figure 18. Appendix A presents the actual data in comparison with the position of the surfaces presented in Figure 18. It can be seen that the surfaces of normalised break forces for all the materials used do not vary significantly from the surfaces before removing the tablets having unusual failure behaviour.

Table 9 Coefficients of the two parameter model of Shang et al. for tablets restricted to failure modes consistent with Hertz's solution for flat faced disks.

\begin{tabular}{|c|c|c|}
\hline Material & $a$ & $b$ \\
\hline Mannitol & 0.369 & 0.131 \\
\hline Calcium phosphate & 0.355 & 0.145 \\
\hline Microcrystalline cellulose & 0.258 & 0.242 \\
\hline
\end{tabular}




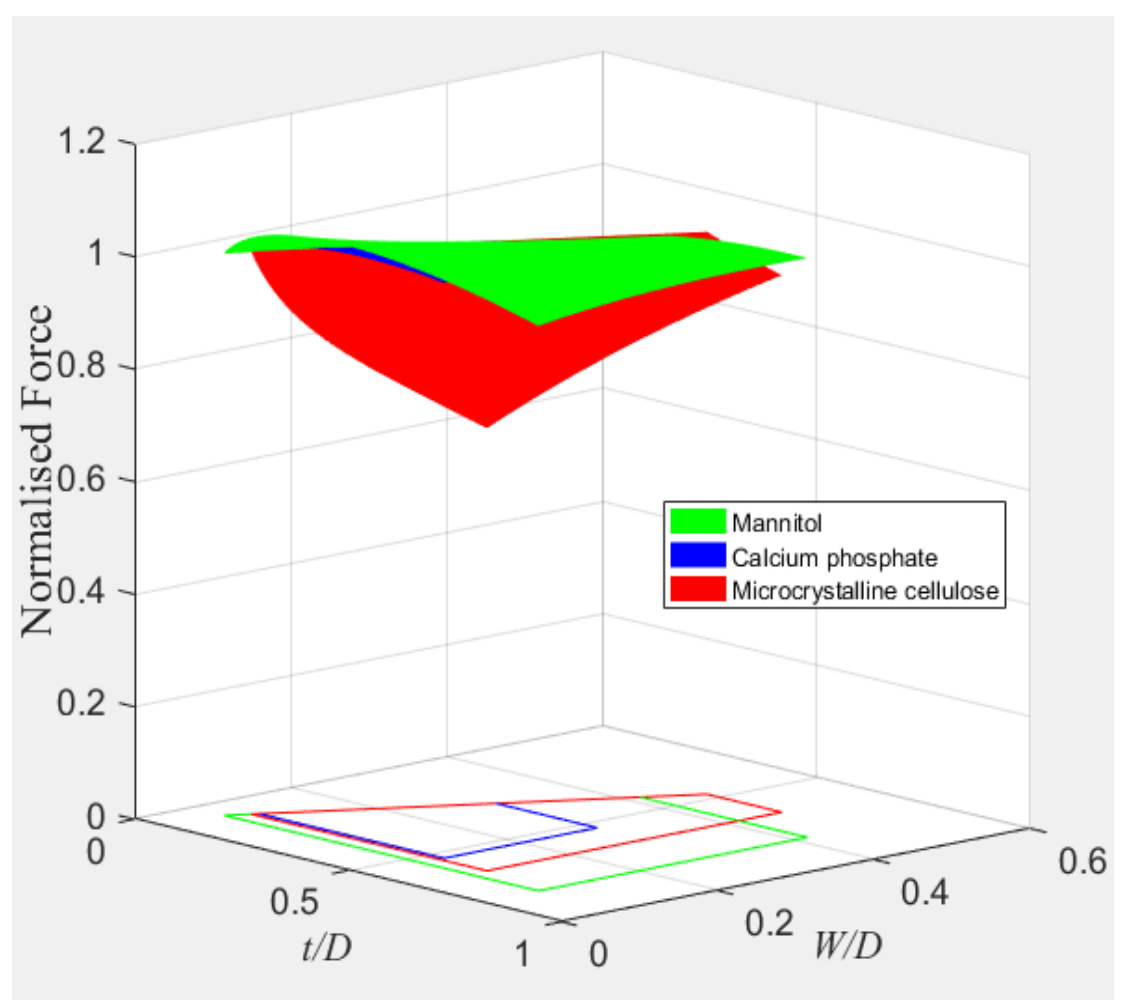

Figure 18. Comparison of normalised break force for mannitol, calcium phosphate, and microcrystalline cellulose after re-fitting.

While repeat experiments give consistent results (see raw data in Figures 11-13), the errors presented in the sections above are indicative of the variations occurring under different experimental conditions.

\subsection{Estimating the coefficients of the two parameter model of Shang et al. for a new material}

Out of the two empirical parameters, by enforcing that $a+b=0.5$ it follows that only one independent parameter is needed (e.g. $a$ ) to predict the break force of a curved faced tablet made of a new material. Using the fitting parameters $c_{d}$ and $n_{d}$ listed in Table 6 , and the fitting parameters $c_{u}$ and $n_{u}$ presented in Table 7, the coefficients $a$ listed in Table 9 are shown in Figure 19 as a function of the dimensionless number $\left(c_{d} / c_{u}\right) *\left(n_{d} / n_{u}\right)$. 


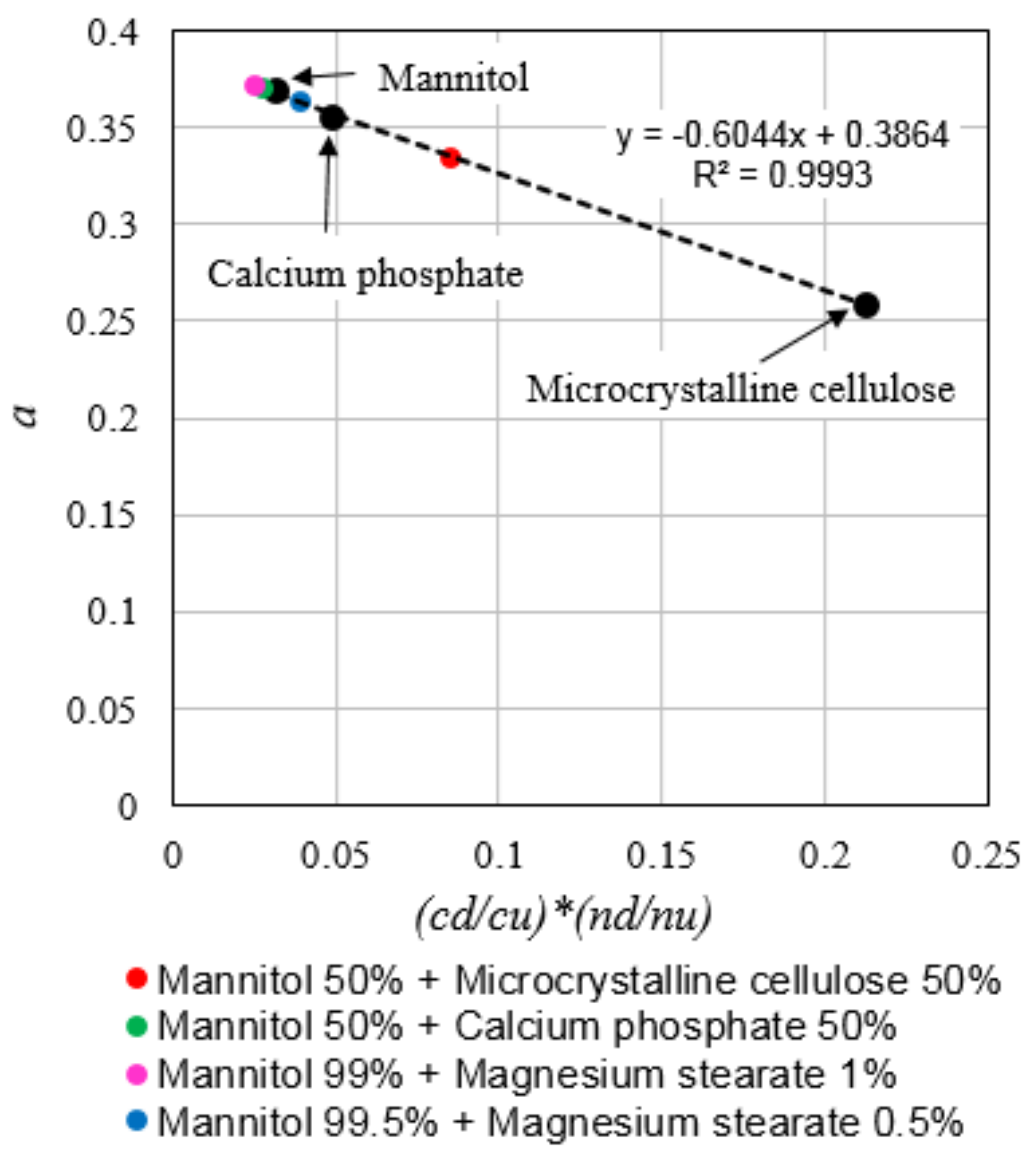

Figure 19. The parameter $a$ versus $\left(c_{d} / c_{u}\right) *\left(n_{d} / n_{u}\right)$.

Parameter a can be fitted with a linear equation for the three pure excipients

$$
a=-0.6044 *\left(c_{d} / c_{u}\right) *\left(n_{d} / n_{u}\right)+0.3864
$$

Knowing the parameters $c_{d}, n_{d}, c_{u}$ and $n_{u}$ listed in Tables 6-7, the values of $a$ and $b$ for mixtures can be estimated using Equation (28). The estimates for mixtures are presented in Table 10.

Table 10. Coefficients $a$ and $b$ calculated for mixtures

\begin{tabular}{|c|c|c|}
\hline Material & $a$ & $\mathrm{~b}$ \\
\hline Mannitol 50\% + Microcrystalline cellulose 50\% & 0.335 & 0.165 \\
\hline Mannitol 50\% + Calcium phosphate 50\% & 0.37 & 0.13 \\
\hline Mannitol 99\% + Magnesium stearate 1\% & 0.371 & 0.129 \\
\hline Mannitol 99.5\% + Magnesium stearate $0.5 \%$ & 0.363 & 0.137 \\
\hline
\end{tabular}

The coefficients $a$ and $b$ for the mixture materials were then used to calculate the predicted break force of curved faced tablets made from the powder mixtures. The approach above is validated using the four mixtures as follows.

The break force was measured for the four mixtures experimentally but for standard curvature only. The experiments were carried out using the same procedures as the three pure powders. The comparison between the predicted and the measured forces is shown in Figure 20 for the four mixtures, respectively. The thickness of the tablets depends on weight and density. The weights are 
labeled individually to provide a more information for further discussion regarding errors. Appendix $B$ shows a more detailed presentation of the actual errors between measured and predicted values of the break force.

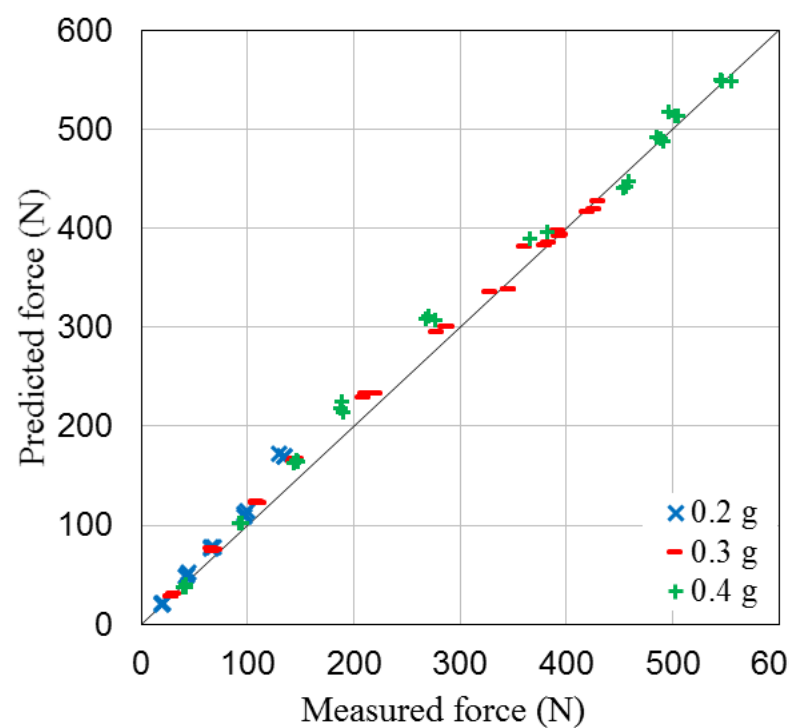

(a) mannitol 50\% + microcrystalline cellulose 50\%.

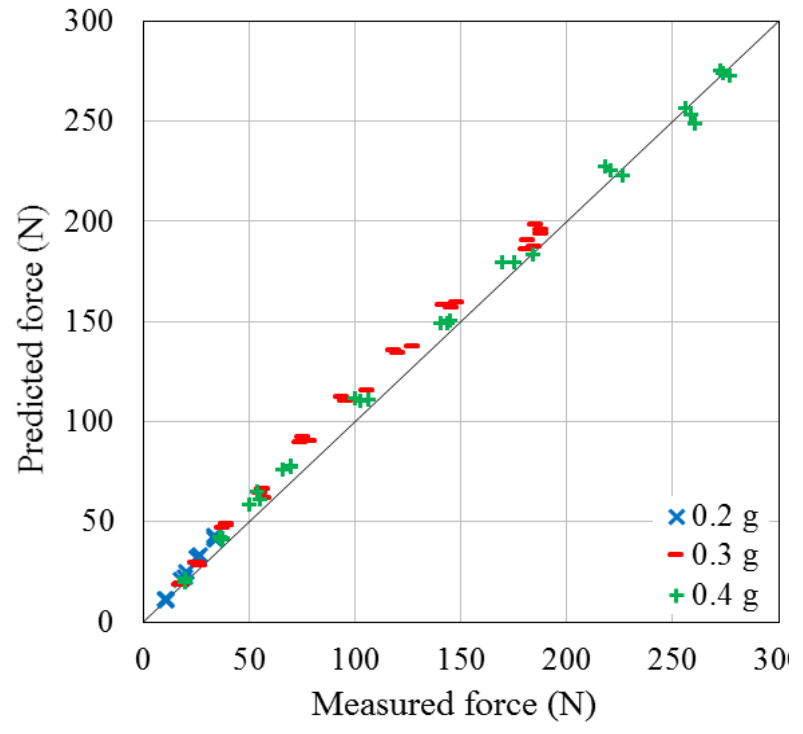

(b) mannitol $50 \%$ + calcium phosphate $50 \%$.

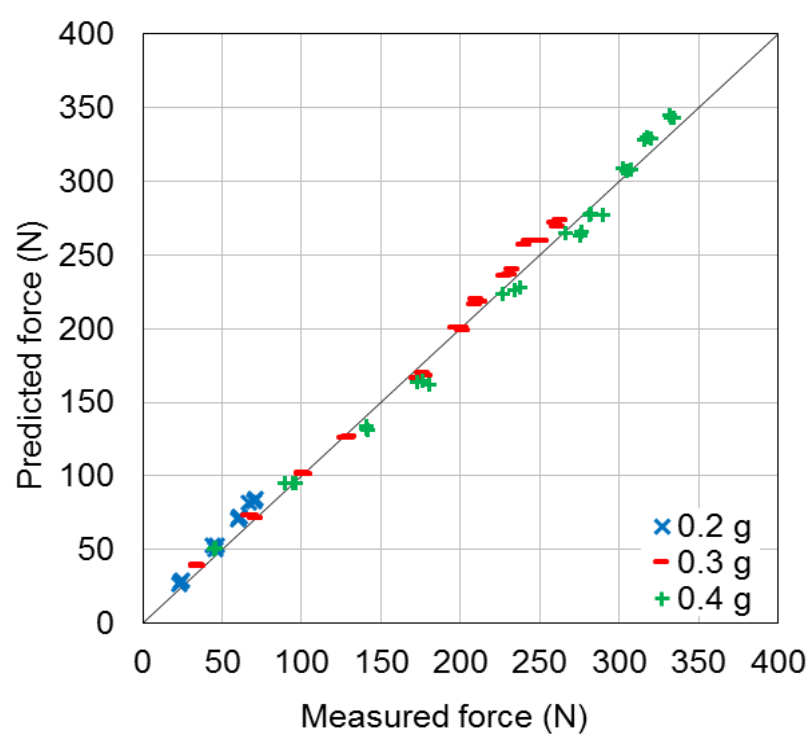

(c) mannitol 99\% + magnesium stearate $1 \%$.

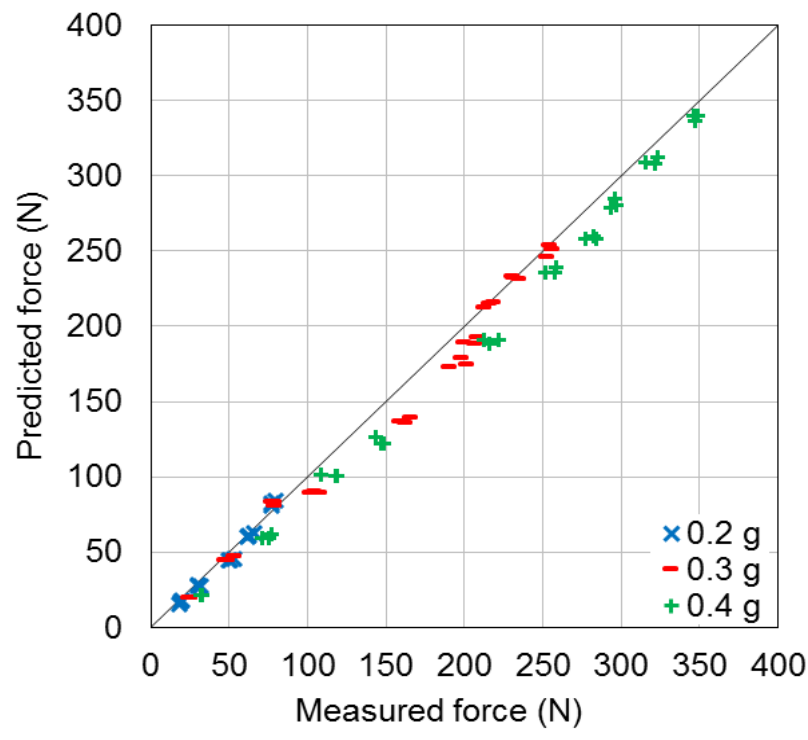

(d) mannitol $99.5 \%$ + magnesium stearate $0.5 \%$.

Figure 20 Predicted force versus measured force for the four mixtures.

Appendix B illustrates graphically the errors in Figure 20 determined as percentage of the difference between measured and predicted break force with respect to the measured break force. The following observations are made:

- mannitol $50 \%+$ microcrystalline cellulose $50 \%$ : at a relative density around 0.6 , a good agreement between the measured and predicted forces can be seen for all tablet weights with an error in the range $1 \%-10 \%$. At relative densities between 0.7 and 0.85 , the values of the predicted force are slightly higher than the values of the measured force with an error in the range (6\%-19\%). In the range of relative densities between 0.85 and 0.95 , values of the 
predicted forces show a good agreement with the measured forces values with error of about $0 \%-7 \%$.

- mannitol $50 \%+$ calcium phosphate $50 \%$ : for all weights, the predicted force values are slightly higher than the measured values with error range of about $1 \%-11 \%$ at relative densities less than 0.6. At a relative densities between 0.6 and 0.7 , the predicted forces are higher than the measured forces for $0.2 \mathrm{~g}$ tablet, with errors of about $13 \%-27 \%$. For $0.3 \mathrm{~g}$ and $0.4 \mathrm{~g}$ tablets, the percentage error between the predicted and measured forces are between $4 \%$ and $24 \%$, and the predicted forces are higher than the measured forces values at relative densities between 0.6 and 0.75 . This material shows a good agreement between the predicted and the measured forces as only small error of about (0\%-7\%) can be seen for both $0.3 \mathrm{~g}$ and $0.4 \mathrm{~g}$ tablets at relative densities between 0.8 and 0.82 .

- mannitol $99 \%+$ magnesium stearate $1 \%$ : at a relative density of 0.65 , it can be observed that the predicted force values are higher than the measured forces values for all tablets with error of about (10\%-17\%). At relative densities between 0.7 and 0.8 , the predicted forces are higher than the measured forces for $0.2 \mathrm{~g}$ tablet, with error of about $10 \%-22 \%$. For the other two weights $0.3 \mathrm{~g}$ and $0.4 \mathrm{~g}$, a relatively good agreement can be observed for relative densities between 0.7 and 0.92 with error of about $2 \%-10 \%$, where values of the predicted forces are sometimes higher and sometimes lower than the measured force values.

- mannitol $99.5 \%$ + magnesium stearate $0.5 \%$ : at a relative density between 0.6 and 0.7 , it can be seen that the predicted forces values are slightly less than the values of the measured forces for $0.2 \mathrm{~g}$ and $0.3 \mathrm{~g}$ tablets with error of about $8 \%-23 \%$. At the same relative density, the values of the predicted forces are less than the measured forces with error between $33 \%$ and $34 \%$ for $0.4 \mathrm{~g}$ tablets. At relative densities between 0.7 and 0.82 , for all tablets, higher values of the measured forces can be and the inverse is true for some values, especially for $0.2 \mathrm{~g}$ and $0.3 \mathrm{~g}$ tablets, where the error was between $2 \%$ and $21 \%$. For relative densities between 0.83 and 0.92 , the predicted and the measured forces show a good agreement with error between $0 \%$ and $16 \%$.

The detailed examination of the errors can reveal tablet geometries and density conditions where errors are smaller or larger. These can be of interest and the potential applicability of the model can be reduced or extended accordingly. It can be observed that the errors are smaller for tablets with typical geometries while for tablets with unusual geometries (e.g. high thickness) the errors are larger. In general the errors become smaller as the density is increased. Typical tablets have relative densities in the region of 0.8-0.9, where the errors become smaller.

The origin of errors at low density needs to be examined further. Low density tablets typically exhibit local flattening at the contacts with the loading platens. This redistributes the applied loads leading to complex failure modes. In fact the causes leading to complex failure patterns discussed in Section 4.4 are believed to contribute also to the errors analysed above.

As described in the introduction there are several relationships that can be used for predicting the break force of curved faced tablet. The method proposed above is compared with Equation 9, which was chosen for comparison because Equation 9 appears in USP. 
Table 11 Comparison of errors between (1) the proposed method using Equation (16) with (2) USP Equation (9) and (3) Equation (16) with fixed parameters $a=0.36$ and $b=0.14$.

\begin{tabular}{|c|c|c|c|c|}
\hline \multirow{2}{*}{ Mixture composition (w/w) } & Error \% & $\begin{array}{c}\text { Proposed } \\
\text { method } \\
\text { Equation 16 }\end{array}$ & $\begin{array}{c}\text { USP method } \\
\text { Pitt's } \\
\text { Equation 9 }\end{array}$ & $\begin{array}{c}\text { Equation } 16 \\
\text { with } a= \\
0.36 \text { and } b= \\
0.14\end{array}$ \\
\hline \multirow{2}{*}{$\begin{array}{c}\text { Mannitol 50\% + Microcrystalline cellulose } \\
\text { 50\% }\end{array}$} & Average & 8.43 & 11.03 & 11.12 \\
\cline { 2 - 5 } Mannitol 50\% + Calcium phosphate 50\% & Std. dev. & 7.21 & 7.71 & 8.46 \\
\cline { 2 - 5 } & Average & 10.91 & 14.64 & 9.71 \\
\cline { 2 - 5 } Mannitol 99\% + Magnesium stearate 1\% & Std. dev. & 8.06 & 10.56 & 7.59 \\
\cline { 2 - 5 } & Average & 6.46 & 12.44 & 5.98 \\
\hline \multirow{2}{*}{ Mannitol 99.5\% + Magnesium stearate 0.5\% } & Std. dev. & 5.8 & 5.87 & 5.21 \\
\cline { 2 - 5 } & Average & 10.06 & 22.50 & 10.29 \\
\hline
\end{tabular}

It is found that errors using the USP method are between 11\%-23\%. The proposed method gives error between $7 \%-11 \%$ for the 4 mixtures considered in this study. However, the USP method requires only tensile strength - density data which is routinely collected during pharmaceutical formulation design and process development. The proposed method requires the same data and in addition the uniaxial compressive strength versus density. The latter can be generated using simple tests but these tests are not performed routinely.

The errors predicted by Equation 16 with fixed parameters are comparable to the errors given by the proposed method. This is not surprising because $a=0.36$ and $b=0.14$ represent the averages for the materials considered and the values of $a$ and $b$ in Table 10 are relatively close to each other. However, materials that behave similar to microcrystalline cellulose will have significantly different values of $a, b$. Thus, in general, the use of Equation 16 with constant values can lead to errors.

Table 11 shows the errors of the USP method considering the full set of data for the four mixtures presented in Figure B2 (Appendix B). A small number of these data points falls outside the range of applicability of Equation $9(0.1 \leq W / D \leq 0.3)$ stated by the Pitt et al. (1989). If these data points are discarded, then the errors for the microcrystalline cellulose mixture become smaller and the errors for the lubricated mannitol become larger. The difference is not significant and the overall conclusions do not change, however.

\section{Summary and conclusions}

The method proposed for predicting the break force of curved faced tablets is summarised for the purpose of practical implementation as follows:

- Determine tensile strength relative density relationships using the routine method of diametrical compression.

- Determine compressive strength relative density relationships using uniaxial compression.

- Fit the above data with curves of the form $\sigma=c\left(R D-R D_{\text {initial }}\right)^{n}$ and determine the dimensionless parameter $\left(c_{d} / c_{u}\right) *\left(n_{d} / n_{u}\right)$.

- Use Equation 28 to estimate parameter $a=-0.6044 *\left(c_{d} / c_{u}\right) *\left(n_{d} / n_{u}\right)+0.3864$. Parameter $b=0.5-a$.

- Use Equation 16: $\sigma_{d}=\frac{F}{\pi D^{2}}\left(a \frac{t}{D}+b \frac{W}{D}\right)^{-1}$ to predict the break force. 
It can be concluded that a method was developed to predict the break force of curved faced tablets following a comprehensive characterisation of the strength of the curved faced tablets made of three pharmaceutical excipients (which were chosen to cover compaction mechanisms ranging from rearrangement of particles to plastic deformation of the particles). The method was validated for 4 mixtures of excipients. The errors were quantified and compared with the prediction of the USP method. The proposed method has improved accuracy but requires additional characterisation of the compressive strength of the powder material.

We demonstrate that the assumption that the "a parameter" is material independent and the premise that the USP method can be used universally to calculate the tensile strength of tablets is in error. In effect any new tablet formulation would require the determination of the "a parameter" such that manufacturing controls on tablet breaking force can be reliably used for monitoring purposes.

\section{Acknowledgements}

The mannitol, calcium phosphate, and microcrystalline cellulose (Avicel PH102) were provided by AstraZeneca. iHolland UK provided the punch set. Muhanad Al-Sabbagh gratefully acknowledges the Iraqi ministry of higher education and scientific research for his PhD studentship. Peter Polak gratefully acknowledges AstraZeneca for his PhD studentship. The authors acknowledge Department of Engineering, University of Leicester, and are grateful to technicians Graham Clark and Vinay Patel for their support.

\section{References}

AKAZAWA, T. 1953. Tension test method for concrete. International Association of Testing and Research Laboratories for materials and structures.

BAKER, T. H. W. 1978. Effect of end conditions on the uniaxial compressive strength of frozen sand.

BASERINIA, R. 2016. Flow of fine cohesive powders under controlled air pressure conditions. PhD thesis. University of Leicester.

CARNEIRO, F. \& BARCELLOS, A. 1953. Concrete tensile strength. RILEM Bulletin, 13, 97-107.

DARVELL, B. 1990. Uniaxial compression tests and the validity of.". Journal of Materials Science, 25, 757-780.

DJEMAI, A. \& SINKA, I. 2006. NMR imaging of density distributions in tablets. International journal of pharmaceutics, Vol. 319, pp. 55-62.

DOREMUS, P., TOUSSAINT, F. \& ALVAIN, O. 2001. Simple tests and standard procedure for the characterisation of green compacted powder. NATO SCIENCE SERIES SUB SERIES III COMPUTER AND SYSTEMS SCIENCES, 176, 29-41.

FELL, J. \& NEWTON, J. 1970. Determination of tablet strength by the diametral-compression test. Journal of Pharmaceutical Sciences, 59, 688-691.

HARIRIAN, I. \& NEWTON, M. 1999. Tensile strength of circular flat and convex-faced avicel PH102 tablets. DARU Journal of Pharmaceutical Sciences, 7, 36-40.

HERTZ, H. 1895. GesammelteWerke (Collected Works), Leipzig.

HONDROS, G., 1959Aust. J. Appl. Sci. 10, 243. 
HUDSON, J., BROWN, E. \& RUMMEL, F. The controlled failure of rock discs and rings loaded in diametral compression. International Journal of Rock Mechanics and Mining Sciences \& Geomechanics Abstracts, 1972. Elsevier, Vol. 9 (02), pp. 241-244, IN1-IN4.

Kuentz M., Leuenberger H. 2000. A new model for the hardness of a compacted particle system, applied to tablets of pharmaceutical polymers. Powder Technology, Vol. 111, Issues 1-2, pp 145-153.

Leuenberger, H., (1982), The compressibility and compactibility of powder systems, Int. J. Pharm., 12 41-55.

Mazel V., Diarra H, Malvestio J. and Tchoreloff P., 2018. Lamination of biconvex tablets: Numerical and experimental study. International Journal of Pharmaceutics, Volume 542, Issues 1-2, pp 66-71.

NEWMAN, K., LACHANCE, L. \& LOVEDAY, R. 1964. Discussion: Strain measurements on saturated concrete specimens*. Magazine of Concrete Research, 16, 243-244.

NEWTON, J.M., Rowley, G., Fell, J.T. Peacock, G., Ridgway, K., 1971. Computer analysis of the relation between tablet strength and compaction pressure. Journal of Pharmacy and Pharmacology. Vol. 23 (S1), pp. 1955-2015.

PITT, K.G. and Heasley M.G. 2013. Determination of the tensile strength of elongated tablets, Powder Technology, Volume 238, Pages 169-175.

PITT, K., NEWTON, J. \& STANLEY, P. 1988. Tensile fracture of doubly-convex cylindrical discs under diametral loading. Journal of materials science, 23, 2723-2728.

PITT, K., NEWTON, J. \& STANLEY, P. 1989. Stress distributions in doubly convex cylindrical discs under diametral loading. Journal of Physics D: Applied Physics, 22, 1114.

PODCZECK, F. 2012. Methods for the practical determination of the mechanical strength of tabletsfrom empiricism to science. International journal of pharmaceutics, 436, 214-232.

PODCZECK, F., DRAKE, K. R. \& NEWTON, J. M. 2013. Investigations into the tensile failure of doublyconvex cylindrical tablets under diametral loading using finite element methodology. International journal of pharmaceutics, 454, 412-424.

PROCOPIO A.T., ZAVALIANGOS A. and CUNNINGHAM J. C., 2003. Analysis of the diametrical compression test and the applicability to plastically deforming materials. Journal of materials Science, Vol. 38, pp3629 - 3639.RAZAVI, S. M., GONZALEZ, M. \& CUITINO, A. M. 2015. General and mechanistic optimal relationships for tensile strength of doubly convex tablets under diametrical compression. International journal of pharmaceutics, 484, 29-37.

ROWE, R. C., SHESKEY, P. J. \& QUINN, M. E. 2009. Handbook of pharmaceutical excipients, Pharmaceutical press.

SHANG, C., SINKA, I.C., JAYARAMAN, B. \& PAN, J. 2013a. Break force and tensile strength relationships for curved faced tablets subject to diametrical compression. International Journal of Pharmaceutics, 442, 57-64.

SHANG, C., SINKA, I.C., \& PAN, J., 2013b, Modelling of the break force of tablets under diametrical compression, International Journal of Pharmaceutics, Vol. 445, pp. 99-107.

SHETTY, D. K., ROSENFIELD, A. \& DUCKWORTH, W. 1986. Mixed-Mode Fracture of Ceramics in Diametral Compression. Journal of the American Ceramic Society, 69, 437-443. 
SINKA, I.C, BURCH, S., TWEED, J. \& CUNNINGHAM, J. 2004a. Measurement of density variations in tablets using X-ray computed tomography. International Journal of Pharmaceutics, Vol. 271, pp. 215224.

SINKA, I.C, CUNNINGHAM, J. \& ZAVALIANGOS, A. 2003. The effect of wall friction in the compaction of pharmaceutical tablets with curved faces: a validation study of the Drucker-Prager Cap model. Powder Technology, Vol. 133, pp. 33-43.

SINKA, I.C., CUNNINGHAM, J. \& ZAVALIANGOS, A. 2004b. Analysis of tablet compaction. II. Finite element analysis of density distributions in convex tablets. Journal of pharmaceutical sciences, Vol. 93 (08), pp. 2040-2053.

TIMOSHENKO, S. \& GOODIER, J. 1970. Theory of Elasticity (3rd) McGraw-Hill. New York.

USP 2011. U.S. Pharmacopeial Convention. The U.S. Pharmacopeia, 34th ed. ed.; U.S. Pharmacopeial Convention: Rockville, MD, USA.

WANG, Q., JIA, X., KOU, S., ZHANG, Z. \& LINDQVIST, P.-A. 2004. The flattened Brazilian disc specimen used for testing elastic modulus, tensile strength and fracture toughness of brittle rocks: analytical and numerical results. International Journal of Rock Mechanics and Mining Sciences, 41, 245-253.

WANG, W. 2007. Towards an Improved Understanding of Strength and Anisotropy. Drexel University.

Wu C.-Y., Ruddy O.M., Bentham A.C., Hancock B.C., Best S.M., Elliott J.A., 2005. Modelling the mechanical behaviour of pharmaceutical powders during compaction. Powder Technology, Volume 152, Issues 1-3, Pages 107-117. 


\section{APPENDICES}

\subsection{Appendix A: Comparison between the break force predicted by the proposed method (using the two parameter model of Shang et al., Equation 16) and the experimental data}

For the purpose of evaluating the agreement between the three surfaces shown in Figure 18 and the experimental data, comparison plots were produced for each material and each punch shape (shallow, standard, deep, extra deep, and ball). These plots are presented in Figures A1-A3 for mannitol, calcium phosphate, and microcrystalline cellulose, respectively. The break forces obtained from the experiments were also normalised using Equation 16 and the tensile strength was obtained using Figure 9.
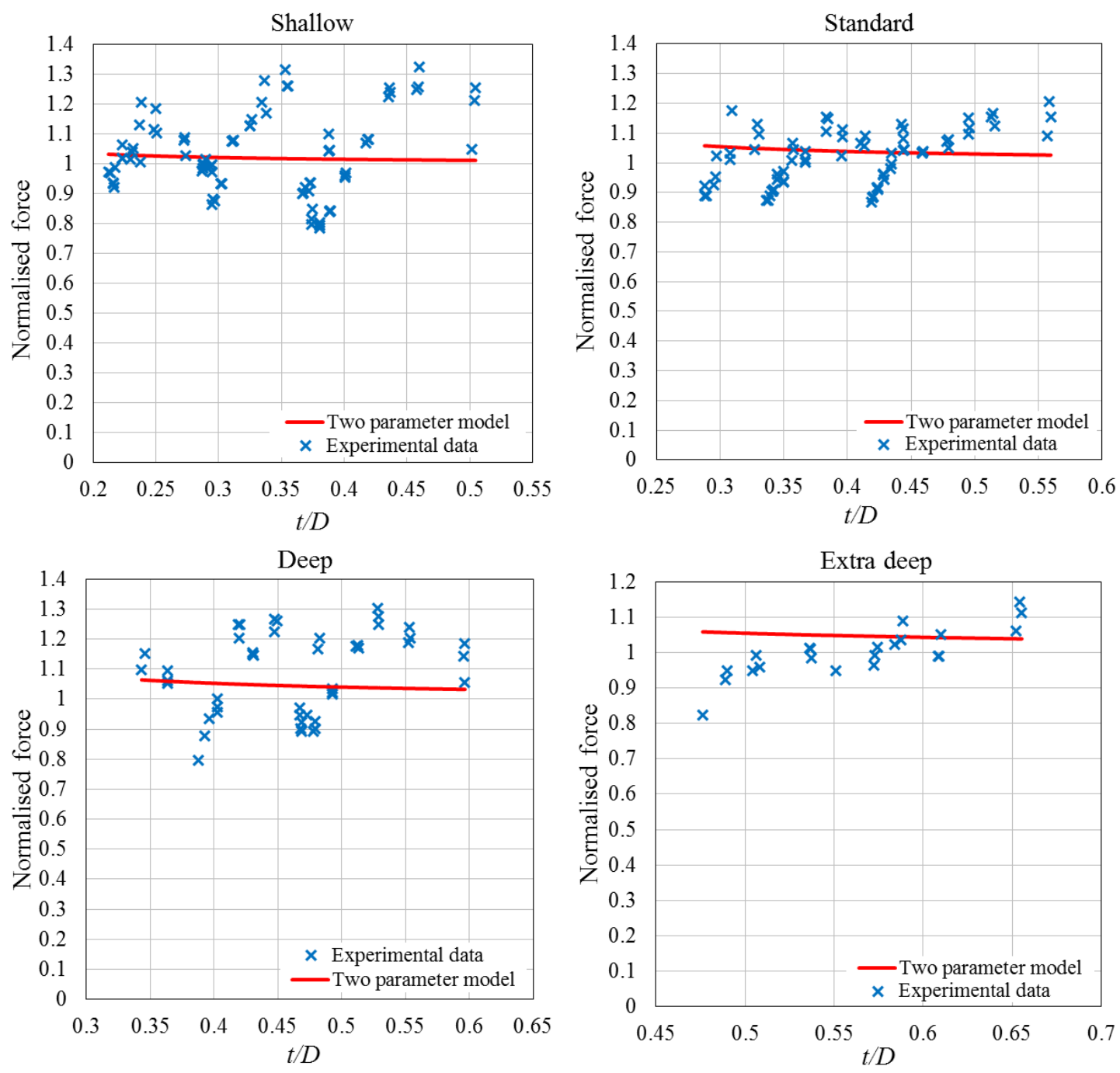


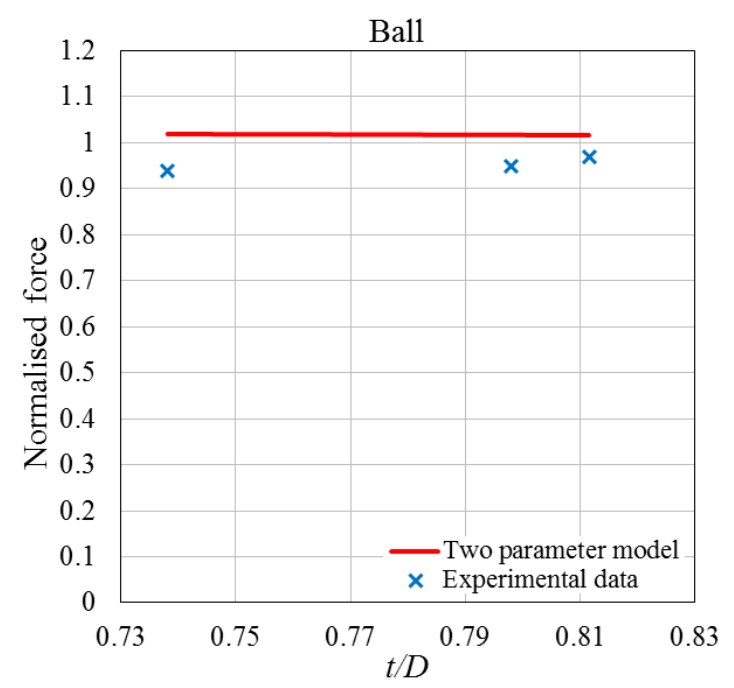

Figure A1. Comparison between experimental data and the two parameter model for mannitol. Labels indicate punch curvature
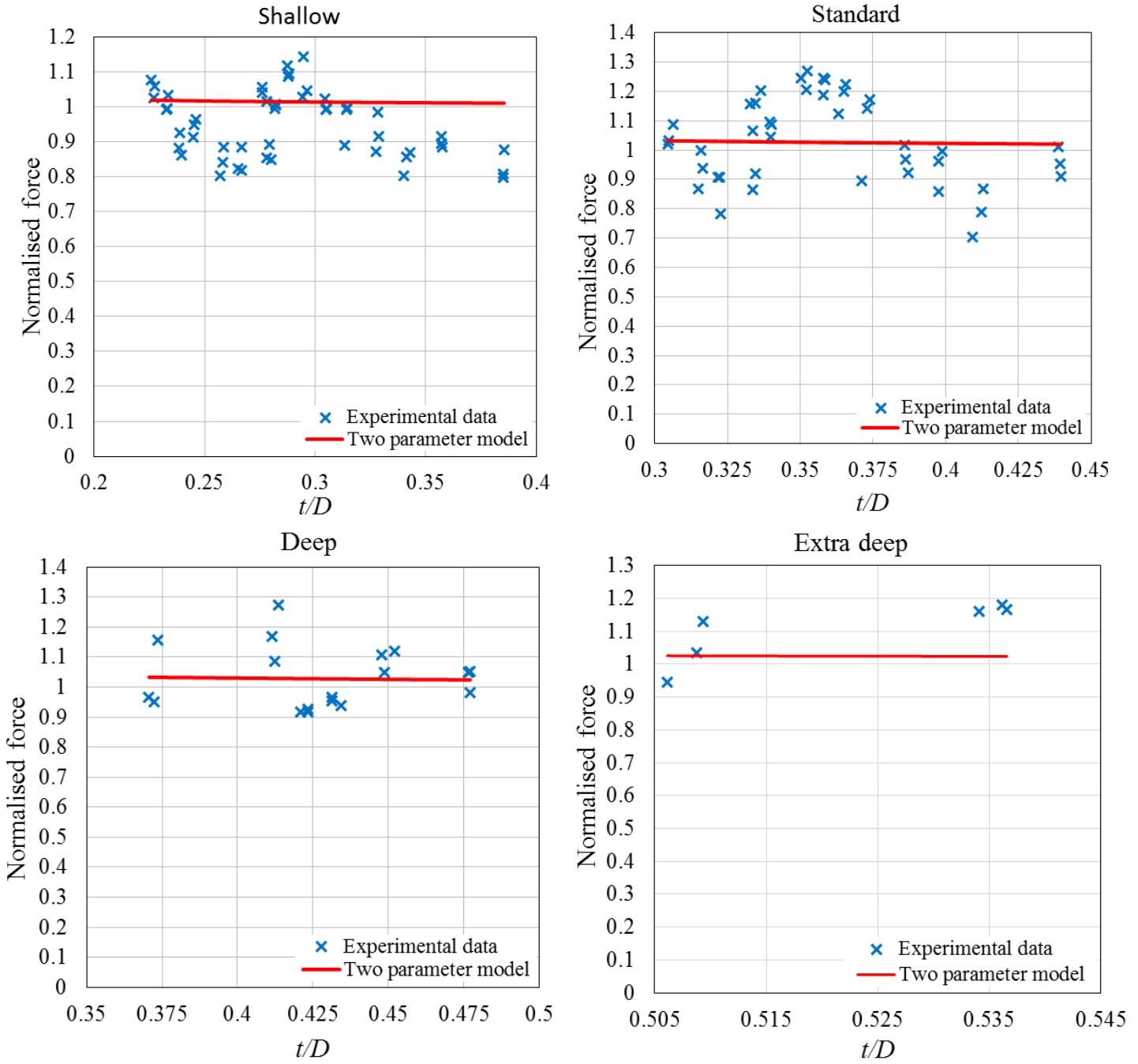

Figure A2. Comparison between experimental data and the two parameter model for calcium phosphate. Labels indicate punch curvature 

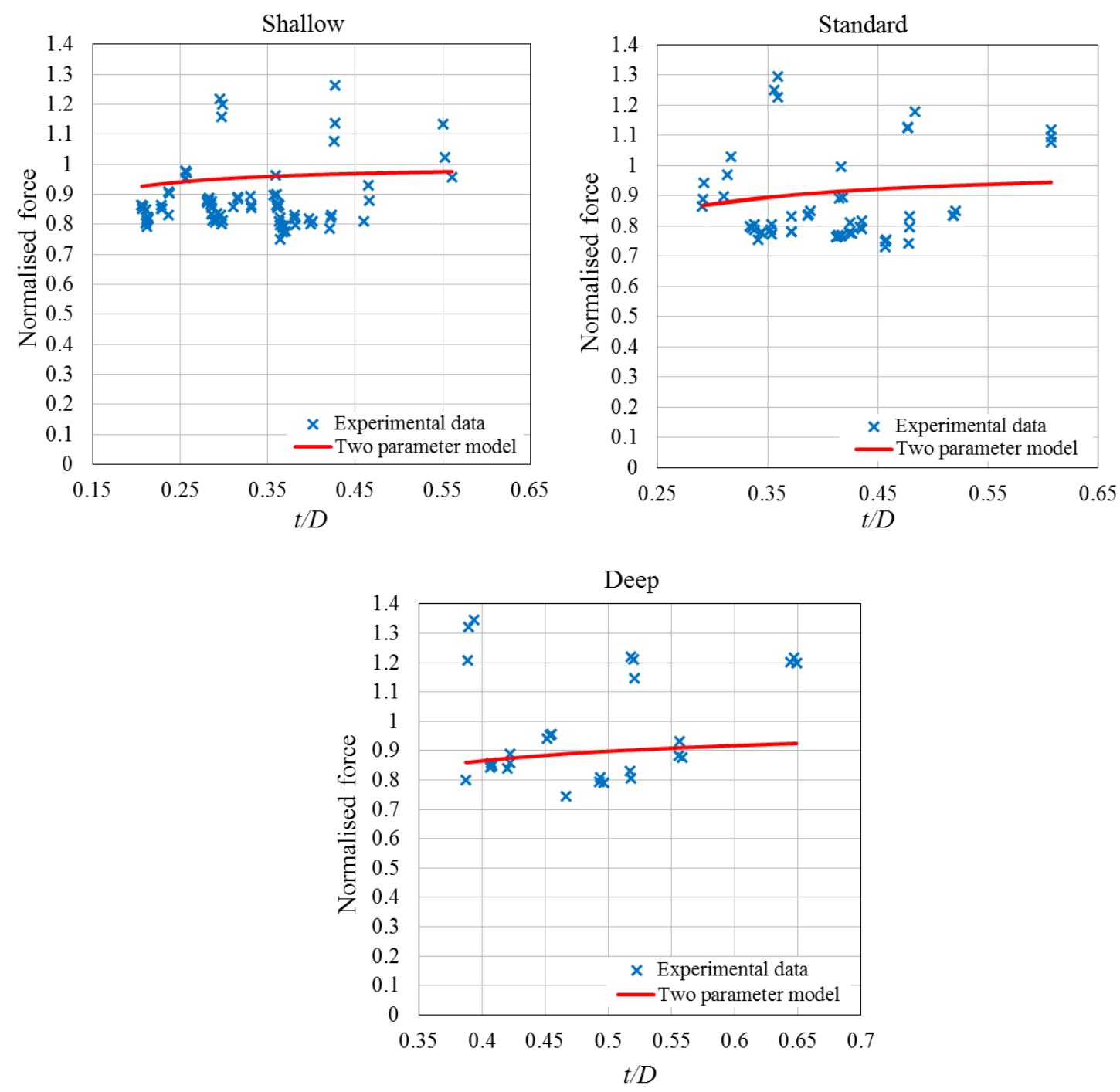

Figure A3. Comparison between experimental data and the two parameter model for microcrystalline cellulose. Labels indicate punch curvature 


\subsection{Appendix B Analysis of errors from the proposed method (using the two parameter model of Shang et al., Equation 16)}

The errors from Figure 20 are presented in Figure B1.

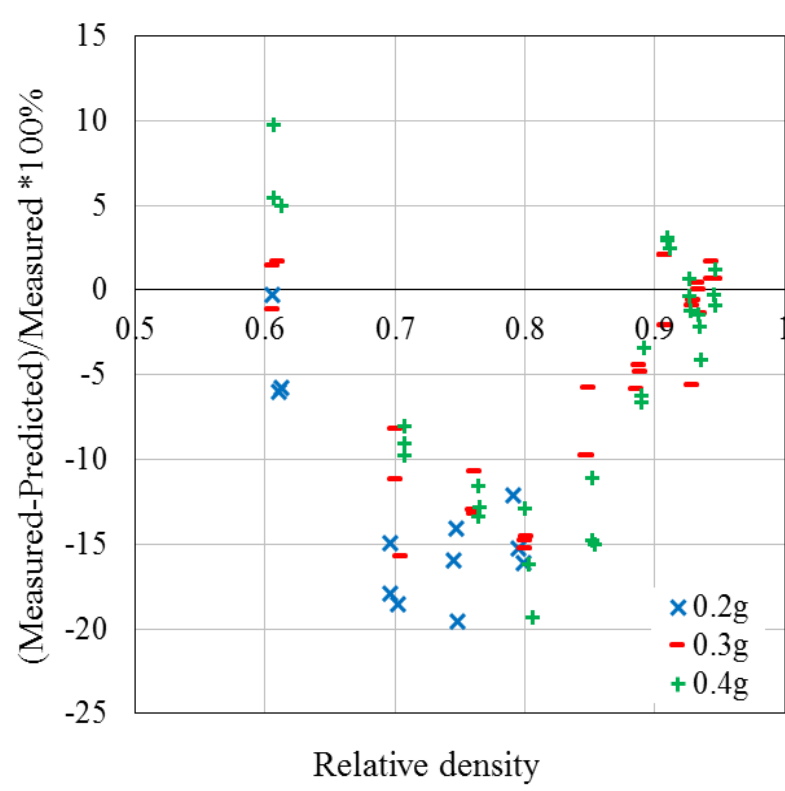

(a) mannitol $50 \%+$ microcrystalline cellulose $50 \%$.

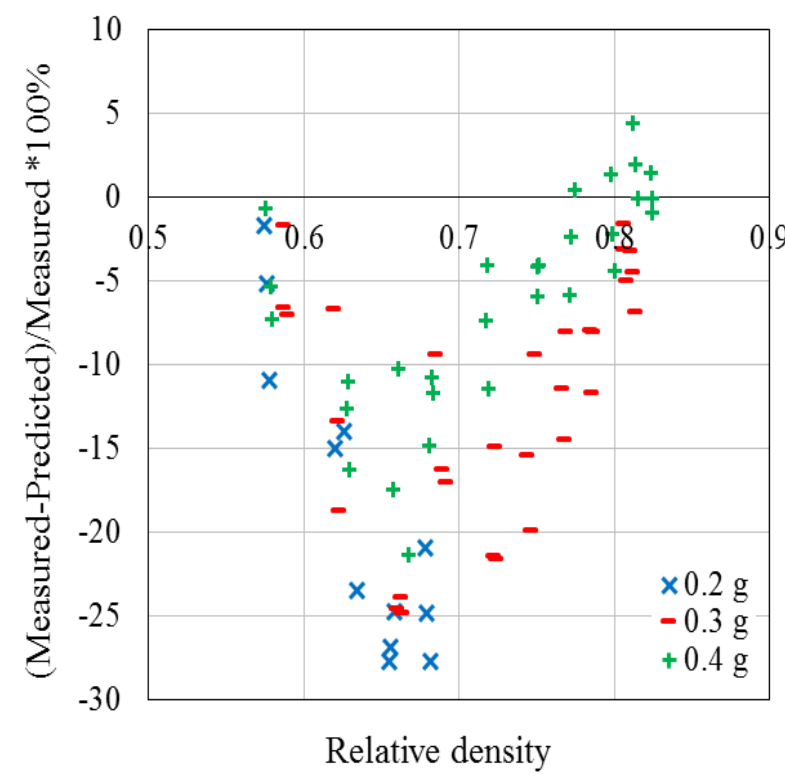

(b) mannitol $50 \%$ + calcium phosphate $50 \%$.

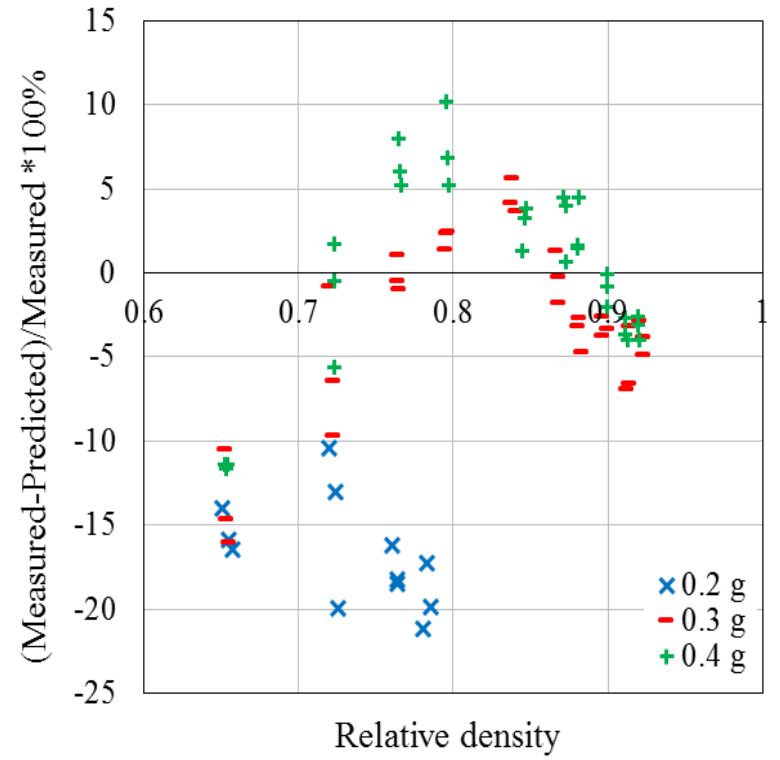

(c) mannitol 99\% + magnesium stearate $1 \%$.

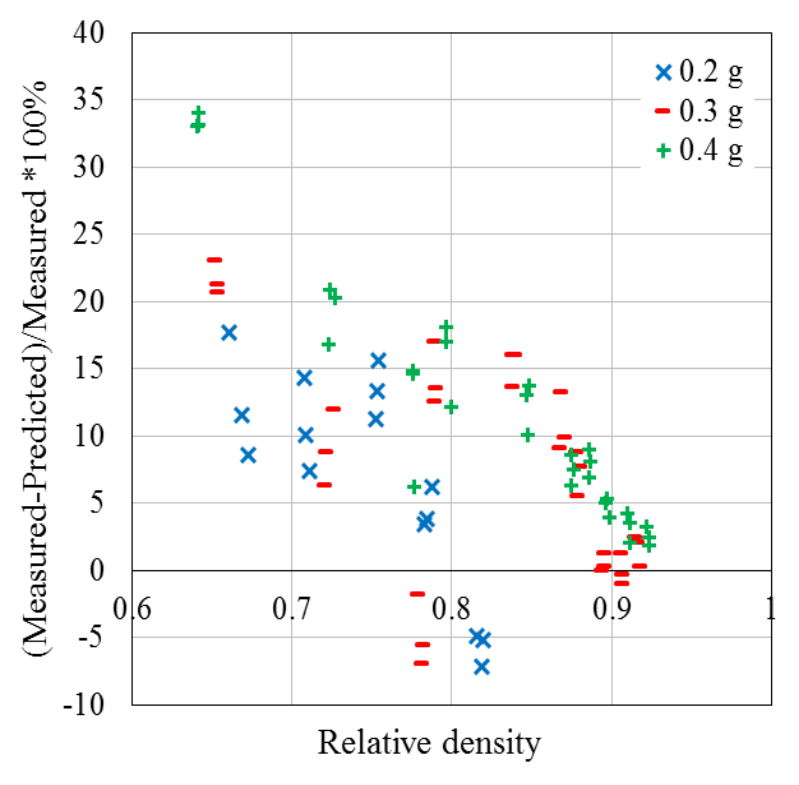

(d) mannitol $99.5 \%$ + magnesium stearate $0.5 \%$.

Figure B1 Errors from the proposed method

In addition, it is instructive to compare the results above with prediction from Shang's equation with fixed parameters $a=0.46$ and $b=0.14$ (these values were chosen as the averages for the four 
mixtures in Table 10). The comparison is illustrated in Figure B2 and the errors are tabulated in Table 11. The errors between the proposed model and the USP method are compared in Appendix $C$.

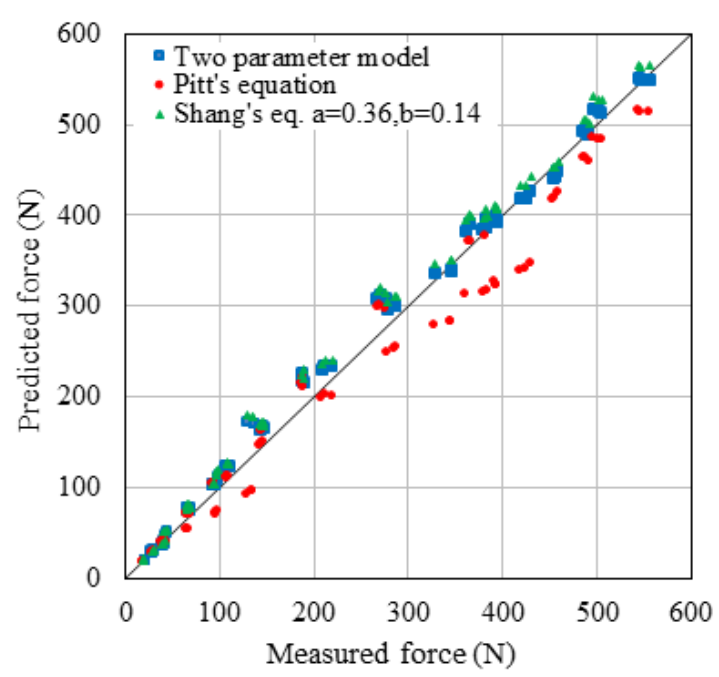

(a) mannitol $50 \%+$ microcrystalline cellulose $50 \%$.

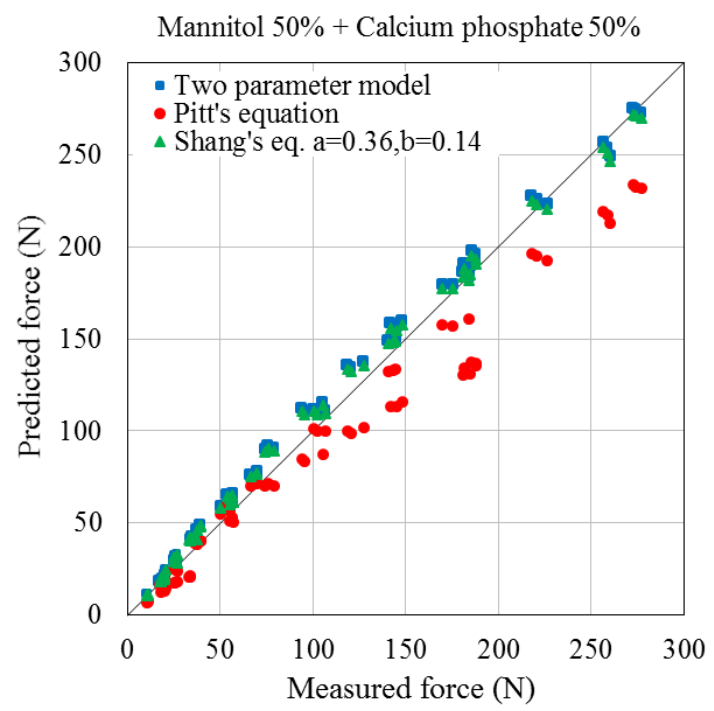

(b) mannitol $50 \%+$ calcium phosphate $50 \%$.

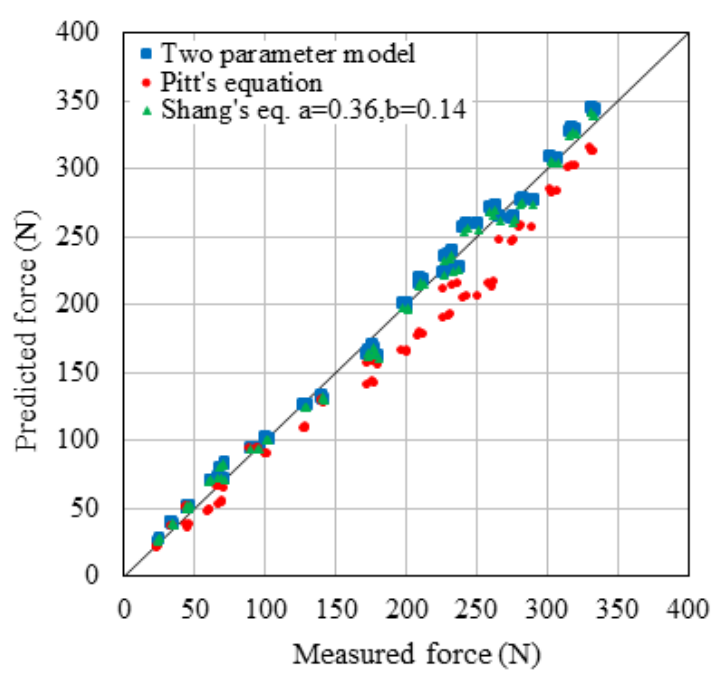

(c) mannitol 99\% + magnesium stearate $1 \%$.

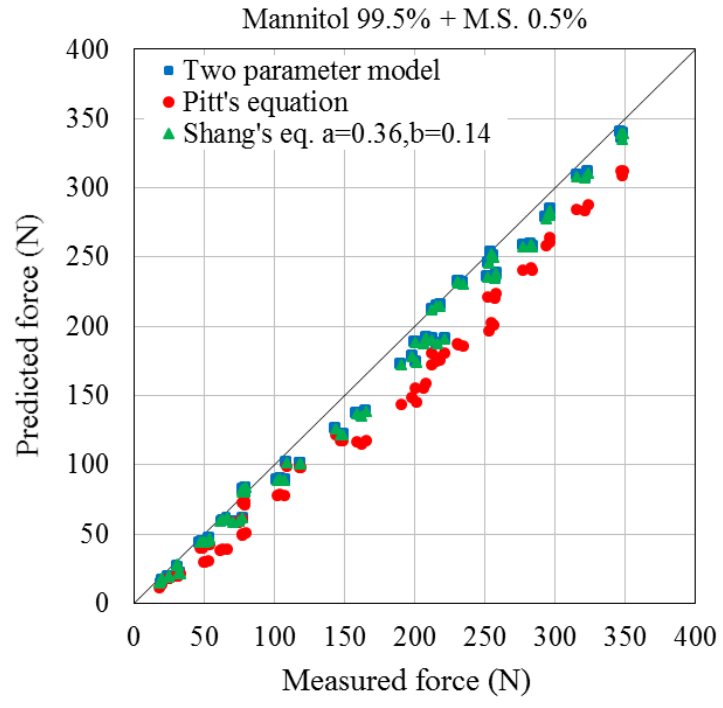

(d) mannitol $99.5 \%+$ magnesium stearate $0.5 \%$.

Figure B2 Comparison of 1) the proposed method with 2) Equation (9) and 3) Equation (16) with fixed parameters $a=0.36$ and $b=0.14$. 


\subsection{Appendix C Error analysis between the proposed method (using the two parameter model of Shang et al., Equation 16) and the USP method (using Equation 9)}
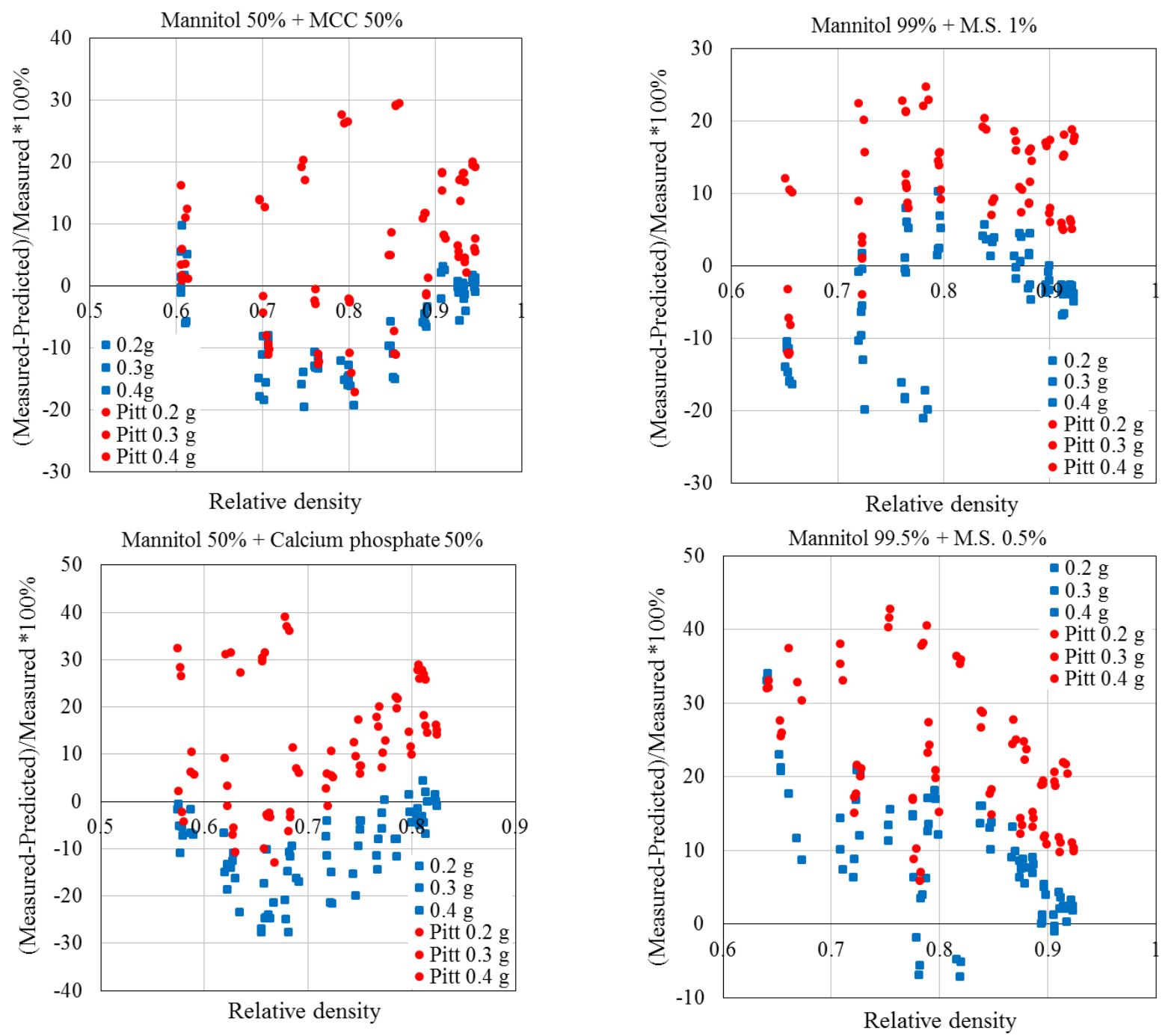

Figure $\mathrm{C} 1$ Comparison of errors from the proposed method labelled using blue squares) and the USP method (labelled using red circles). 